\title{
The Adriatic Sea modelling system: a nested approach
}

\author{
M. Zavatarelli and N. Pinardi \\ Università degli Studi di Bologna, Laboratorio di Simulazioni Numeriche del Clima e degli Ecosistemi Marini, Piazza \\ J. F. Kennedy 12, Palazzo Rasponi, I-40800 Ravenna, Italy
}

Received: 23 August 2001 - Revised: 23 September 2002 - Accepted: 24 September 2002

\begin{abstract}
A modelling system for the Adriatic Sea has been built within the framework of the Mediterranean Forecasting System Pilot Project. The modelling system consists of a hierarchy of three numerical models (whole Mediterranean Sea, whole Adriatic Sea, Northern Adriatic Basin) coupled among each other by simple one-way, off-line nesting techniques, to downscale the larger scale flow field to highly resolved coastal scale fields. Numerical simulations have been carried out under climatological surface forcing. Simulations were aimed to assess the effectiveness of the nesting techniques and the skill of the system to reproduce known features of the Adriatic Sea circulation phenomenology (main circulation features, dense water formation, flow at the Otranto Strait and coastal circulation characteristics over the northern Adriatic shelf), in view of the pre-operational use of the modelling system. This paper describes the modelling system setup, and discusses the simulation results for the whole Adriatic Sea and its northern basin, comparing the simulations with the observed climatological circulation characteristics. Results obtained with the northern Adriatic model are also compared with the corresponding simulations obtained with the coarser resolution Adriatic model.
\end{abstract}

Key words. Oceanography: general (continental shelf processes; numerical modelling) - Oceanography: physical (general circulation)

\section{Introduction}

The Adriatic Sea (Fig. 1) is one of the major regional subbasins of the Mediterranean Sea. It is a NW-SE elongated basin, almost entirely surrounded by mountain ridges and communicating with the Mediterranean basin (Ionian Sea) through the Otranto Strait.

Correspondence to: M. Zavatarelli

(M.Zavatarelli@ambra.unibo.it)
Its morphology and the characteristics of the forcing functions acting on the basin determine several notable differences with respect to the whole Mediterranean basin. While the Mediterranean Sea is almost everywhere characterized by a reduced extension of the continental shelf, the northern part of the Adriatic basin lies entirely on the shelf and is characterized by very shallow depths ( $35 \mathrm{~m}$ on the average). In the central part depths are gently increasing to $100 \mathrm{~m}$, and the distinctive morphological features are two small bottom depressions (the so-called "Pomo" or "Jabuka" Pits) having a maximum depth of $250 \mathrm{~m}$. The southern part of the basin contrasts markedly with the northern one, as depths rapidly increase to maximum values of about $1200 \mathrm{~m}$. The connection with the Ionian Sea in the Otranto Strait is characterized by a sill having a depth of $875 \mathrm{~m}$.

The surface heat exchange between the sea and the atmosphere determines a net heat loss, estimated by Artegiani et al. (1997a) and Maggiore et al. (1998) on an annual basis at $-22 \mathrm{~W} / \mathrm{m}^{2}$. Monthly values ranges between -250 (winter) and 200 (summer) $\mathrm{W} / \mathrm{m}^{2}$. The Adriatic Sea has, therefore, a negative heat budget, a characteristic consistent with the whole Mediterranean Sea.

On the contrary, the fresh water budget differs strongly from the overall Mediterranean Sea budget. In fact, the Adriatic Sea shows a significant net fresh water gain, while the whole Mediterranean basin is characterized by a net fresh water loss. Raicich (1996) has estimated the net annual fresh water gain of the Adriatic Sea to be greater than $1 \mathrm{~m}$, mostly determined by the strong river runoff contribution, since evaporation and precipitation almost cancel each other on an annual basis. The climatology of the river runoff into the Adriatic Sea, compiled by Raicich (1994), is shown in Table 1. It indicates that most of the runoff is concentrated in the northern Adriatic Sea, but there are significant contributions also in the southern basin due to the rivers located along the Albanian coast, north of the Otranto Strait. The major river discharging in the basin is the Po, with an annually averaged runoff of $1585 \mathrm{~m}^{3} / \mathrm{s}$ (see Table 1).

The mountain ridges surrounding the basin determine a 


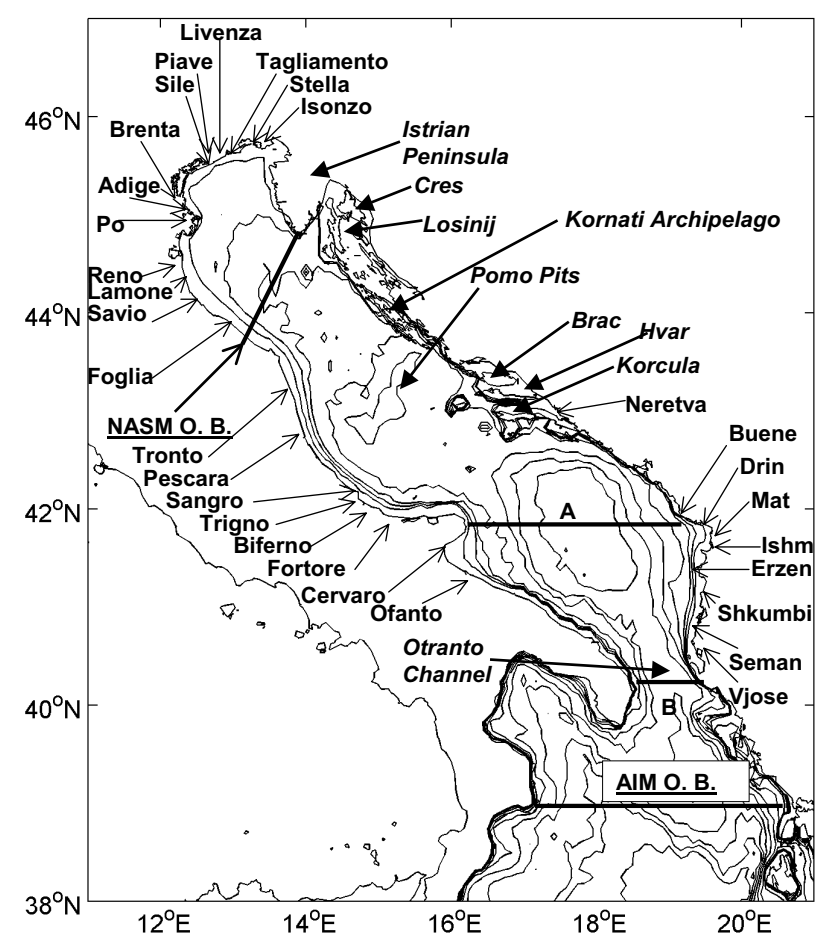

Fig. 1. The Adriatic Sea coastal and bottom morphology. The figure also shows the approximate location of the Adriatic Rivers' mouth discharging into the basin, the location of the AIM and NASM open boundaries (AIM O.B. and NASM O.B., respectively), the location of the sections shown in Fig. 12 (A) and Fig. 13 (B) and the location of the islands retained by the AIM model geometry.

strong topographic control of the wind field. Cavaleri et al. (1996) described the two major wind regimes affecting the Adriatic basin. During winter, the dominating wind is the socalled "Bora" or "Bura", a NE wind affecting particularly the northern Adriatic in winter with intense episodic events. The other main wind blowing over the basin mainly in spring and autumn is a SE wind (the so-called "Scirocco" or "Sirocco"), channelled along the major axis of the basin.

Despite the strong fresh water gain, the Adriatic Sea is a site of dense water formation. The formation occurs at two distinct locations: the shallow northern Adriatic (Artegiani et al., 1989) and the deeper southern Adriatic (Ovchinnikov et al., 1987; Manca et al., 2001). According to the definition given by Killworth (1983) (but see also Malanotte Rizzoli, 1991), the dense water formation in the northern Adriatic Sea is characterized by intense surface cooling and subsequent sinking along the continental shelf, while the process occurring in the southern Adriatic is characterized by opensea-like vertical convection.

The seasonal climatological general circulation has been defined by Artegiani et al. (1997a, b), on the basis of historical hydrological observations, and by Poulain (2001) on the basis of trajectories of satellite tracked drifters released in the Adriatic Sea over the decade 1990-1999. Their description of the seasonal surface circulation are not directly compa-
Table 1. Annually averaged runoff into the Adriatic Basin (From Raicich, 1994)

\begin{tabular}{|c|c|}
\hline Fresh water Source & $\begin{array}{l}\text { Averaged annual } \\
\text { Runoff }\left(\mathrm{m}^{3} / \mathrm{s}\right)\end{array}$ \\
\hline Vjosë & 182 \\
\hline Seman & 200 \\
\hline Shkumbi & 61 \\
\hline Erzen & 20 \\
\hline Ishm & 14 \\
\hline Mat & 64 \\
\hline Drin & 338 \\
\hline Buenë & 44 \\
\hline Neretva & 378 \\
\hline \multicolumn{2}{|l|}{ Diffused runoff } \\
\hline from Neretva to Istria & 1077 \\
\hline \multicolumn{2}{|l|}{ Diffused runoff } \\
\hline for Istrian coast & 187 \\
\hline Isonzo & 204 \\
\hline Stella & 36 \\
\hline \multicolumn{2}{|l|}{ Diffused runoff between } \\
\hline Isonzo and Tagliamento & 26 \\
\hline Tagliamento & 97 \\
\hline Livenza & 88 \\
\hline \multicolumn{2}{|l|}{ Diffused runoff between } \\
\hline Tagliamento and Piave & 45 \\
\hline Piave & 55 \\
\hline Sile & 53 \\
\hline \multicolumn{2}{|l|}{ Diffused runoff between } \\
\hline Piave and Brenta & 52 \\
\hline Brenta & 93 \\
\hline \multicolumn{2}{|l|}{ Diffused runoff between } \\
\hline Brenta and Adige & 49 \\
\hline Adige & 234 \\
\hline \multicolumn{2}{|l|}{ Diffused runoff between } \\
\hline Adige and Po & 26 \\
\hline Po & 1585 \\
\hline Reno & 49 \\
\hline Lamone & 36 \\
\hline \multicolumn{2}{|l|}{ Diffused runoff between } \\
\hline Po and Tronto & 138 \\
\hline Foglia & 7 \\
\hline Tronto & 18 \\
\hline Pescara & 54 \\
\hline \multicolumn{2}{|l|}{ Diffused runoff between } \\
\hline Pescara and Fortore & 100 \\
\hline Sangro & 11 \\
\hline Trigno & 11 \\
\hline Biferno & 14 \\
\hline Fortore & 12 \\
\hline Cervaro & 3 \\
\hline Ofanto & 16 \\
\hline TOTAL & 5676 \\
\hline
\end{tabular}

rable, since Artegiani et al. (1997a, b) treated the baroclinic component (dynamic height) of the general circulation, while the lagrangian observations of Poulain (2001) provide a view 
of the complete surface velocity field. However, the circulation pattern emerging from these two independent analyses show some general points of agreement, notably the overall cyclonic character of the general circulation, mainly constituted by three cyclonic gyres located in the southern, central and northern sub-basins, named, respectively, by Artegiani et al. (1997b) Southern (SAd), Middle (MAd) and Northern (NAd) Adriatic gyres. The three gyres are interconnected among each other (with seasonally varying characteristics) by two coastal currents, one flowing southward along the whole western coast from the Po River delta to the Otranto Strait (named Western Adriatic Coastal current or WACC), the other flowing northward from the Otranto Strait along the eastern coast and reaching the central Adriatic sub-basin (named Eastern Southern Adriatic Current or ESAC).

Here we describe the implementation and discuss the numerical simulation results obtained with a modelling system of the Adriatic Sea. The system has been constructed within the framework of the EU sponsored "Mediterranean Forecasting System Pilot Project" (Pinardi et. al., 2003) and consists of the following three numerical models:

1. Whole Mediterranean Sea general circulation model (hereafter named Ocean General Circulation Model, OGCM), at approximately $12.5 \mathrm{~km}$ resolution;

2. Whole Adriatic Sea Model (hereafter named Adriatic Intermediate Model, AIM), at approximately $5 \mathrm{~km}$ resolution;

3. Northern Adriatic Sea Model (hereafter named Northern Adriatic Shelf Model, NASM), at approximately $1.5 \mathrm{~km}$ resolution.

The three models are coupled by simple one-way, off-line nesting techniques that are described in the following.

By "nesting" we mean a numerical technique based on finite differences aimed to simulate (with high resolution) a limited area domain embedded into a larger (and coarsely resolved) model domain (Pullen, 2000), so that the simulated "nested" model circulation is influenced (through proper specification of open boundary conditions) by the larger scale circulation simulated by the coarser resolution "nesting" model. Nesting techniques have been largely used in numerical weather prediction and their use in numerical oceanography (see, for instance, Oey et al., 1992 and Oey, 1998) is expanding in view of the increased use of numerical ocean models to simulate and forecast limited coastal areas (Pullen and Allen, 2000; 2001). The transfer of information from the "nesting" to the "nested" model involves data interpolation on the "nested" model open boundary. Inaccuracies in the interpolation might generate errors leading to violation of mass conservation or to generation of distortions of the model solution at the open boundary (Pullen, 2000). In the present study, the time varying specification of temperature, salinity, surface elevation and velocity fields, arising from the coarse resolution model on the open boundary of the finer resolution one was designed in a way to satisfy the volume conservation constraint and to allow disturbances, arising from possible dynamical inconsistencies between the two models solutions, to move out of the domain, in order not to affect the "nested" model simulation (see Sect. 2.6 for details on the volume conservation constraint and the nesting technique).

Part of this work builds on the previous modelling experience in the Adriatic Sea carried out by Zavatarelli et al. (2002), who developed climatological numerical simulations of the Adriatic Sea general circulation already utilizing oneway nesting techniques with OGCM data specified on the model open boundary. Such model implementation constitutes the basis of the AIM nesting and has been also transferred to the NASM. However, an important change (detailed below) in the advective numerical scheme for tracers has been implemented into both the AIM and the NASM.

This climatological study is needed to assess the robustness of the nesting technique and methods, before starting near real-time short-term forecasts. Indeed, we want to be sure that errors in the open boundary conditions can be controlled at seasonal time scales. Following a consolidated experience in numerical modelling, the climatological simulations will serve as a basis to initialize interannual forcing simulations, in order to minimize the numerical adjustment to the rapidly evolving forcing.

Section 2 describes the characteristics of the models used, and details of the OGCM, AIM and NASM implementation and the forcing functions. In Sect. 3 the seasonal variability of the circulation resulting from the AIM and NASM simulations are described and compared. Finally, in Sect. 4 we offer conclusions.

\section{Models design}

\subsection{The Ocean General Circulation Model (OGCM)}

The numerical model used for the climatological simulations of the Mediterranean Sea General circulation is based upon the rigid lid Modular Ocean Model, MOM, as implemented in the Mediterranean Sea by Demirov and Pinardi (2002). The OGCM has a horizontal grid with a resolution of $1 / 8^{\circ}$ and 31 vertical levels (Pinardi et al., 2003). It has been forced by the same monthly means of wind stress and heat flux used for the AIM, while the salinity flux has been parameterized by relaxing the surface salinity to monthly climatological data obtained from the MED6 (Brankart and Pinardi, 2001) data set. It has to be stressed that the OGCM model domain covers the Adriatic Sea up to about $43.5^{\circ} \mathrm{N}$ and, therefore, excludes almost entirely the northern Adriatic basin. This did not allow for the initialization of AIM from the OGCM fields. A detailed description of the OGCM can be found in Pinardi et al. (2003), and it has been used to produce 7 years of simulated fields, the last of which was used to provide open boundary conditions for the AIM. 
Table 2. The AIM and NASM implementation characteristics

\begin{tabular}{cll}
\hline$\Delta x, \Delta y$ & Horizontal resolution (approx) & $5.0 \mathrm{~km}$ (AIM) \\
& & $1.5 \mathrm{~km}$ (NASM) \\
\hline$\sigma$ & Sigma layers & 21 (AIM) \\
& & 11 (NASM) \\
\hline$\Delta t_{\mathrm{ext}}$ & External mode time step & $9 \mathrm{~s}(\mathrm{AIM})$ \\
& & $15 \mathrm{~s}(\mathrm{NASM})$ \\
\hline$\Delta t_{\text {int }}$ & Internal mode time step & $900 \mathrm{~s}(\mathrm{AIM})$ \\
& & $495 \mathrm{~s}(\mathrm{NASM})$ \\
\hline \multirow{2}{*}{$\mathrm{C}$} & Non-dimensional constant used in calculating & $0.10(\mathrm{AIM})$ \\
& the horizontal viscosity for momentum & 0.01 (NASM) \\
\hline \multirow{2}{*}{$\mu_{M}$} & Background vertical diffusivity & $10^{-5} \mathrm{~m}^{-2} \mathrm{~s}^{-1}$ \\
\hline$Z_{0}$ & Bottom roughness length & $0.010 \mathrm{~m}^{(\mathrm{AIM})}$ \\
& & $\left.0.001 \mathrm{~m}^{\mathrm{NASM}}\right)$ \\
\hline$\lambda$ & Solar radiation attenuation coefficient & $0.042 \mathrm{~m}^{-1}$ \\
\hline $\mathrm{Tr}$ & Non-dimensional transmission coefficient for & 0.31 \\
& solar radiation penetration & \\
\hline
\end{tabular}

2.2 The Adriatic Intermediate Model (AIM) and the Northern Adriatic Shelf Model (NASM)

The ocean model used for both the AIM and the NASM is the Princeton Ocean Model, POM (Blumberg and Mellor, 1987). It is a three-dimensional finite difference, free surface numerical model, utilizing the Boussinesq and the hydrostatic approximation and a split mode time step. The model contains a second order turbulence closure submodel, providing the vertical mixing coefficients (Mellor and Yamada, 1982). The stability functions used in the turbulence closure are those described in Galperin et al. (1988). No horizontal diffusion was applied to the temperature and salinity fields, while for momentum the parameterization of Smagorinsky (1993), implemented into POM according to Mellor and Blumberg (1986) has been used. Density is calculated by an adaptation of the UNESCO equation of state devised by Mellor (1991). A description of the model code can be found in Mellor (1998). A listing of the model free parameters adopted in the AIM and NASM implementation is given in Table 2.

With respect to the standard version of POM, an important change in the model structure has been implemented into both AIM and NASM. The default POM centered difference scheme for the advection of tracers has been substituted with the Smolarkiewicz (1984) and Smolarkiewicz and Clark (1986) flux corrected upstream scheme (characterized by small implicit diffusion), as coded into POM by Sannino et al. (2002). The scheme is iterative. The first iteration consists of a standard upstream scheme, while the successive iterations reapply the upstream scheme using an anti-diffusive velocity. In the present study the number of total iterations was set to three. The use of this scheme was dictated by the need for carefully computing tracers in regions characterized by sharp horizontal and vertical density gradients, such as those occurring in the Adriatic Sea areas affected by strong freshwater input. Previous experiments carried out utilizing the centered difference advection scheme (not shown here), did not give entirely satisfactory results in terms of simulated temperature and salinity fields.

\subsection{The AIM and NASM grid and bathymetry}

Both the AIM and the NASM use grids with rectangular horizontal resolution. The AIM grid has a resolution of approximately $5 \mathrm{~km}$ (about $1 / 20^{\circ}$ ). The model domain encompasses the whole Adriatic basin and extends south of the Otranto channel into the northern Ionian Sea, where the only open boundary is located (see Fig. 1). The Croatian Islands retained by the AIM geometry are explicitly indicated in Fig. 1.

The NASM grid has a resolution of approximately $1.5 \mathrm{~km}$ (about $1 / 37^{\circ}$ ). The model is domain rotated by $67^{\circ}$ with respect to the AIM grid and extends over the northern Adriatic Sea. The only open boundary (see Fig. 1) cuts the basin across an ideal line spanning from the southern tip of the Istrian peninsula to the Italian coast, approximately at $43.6^{\circ}$ lat. $\mathrm{N}$.

In the vertical, POM uses a bottom following, sigmacoordinate system $\sigma=(z-\eta) /(H+\eta)$, where $H(x, y)$ is the bottom topography and $\eta(x, y, t)$ is the free surface elevation. In the present study AIM has 21 vertical sigma levels, while 11 vertical sigma levels define the NASM vertical resolution. In both models the sigma levels are more compressed (logarithmic distribution) near the surface and the bottom. The sigma layers distribution in the two models is listed in Table 3.

The bottom geometry for both models was obtained from the U.S. Navy unclassified $1 / 60^{\circ}$ bathymetric database 
Table 3. Sigma layers distribution in AIM and NASM

\begin{tabular}{rrr}
\hline$\sigma$ & AIM & NASM \\
\hline 1 & 0.000 & 0.000 \\
2 & -0.008 & -0.060 \\
3 & -0.017 & -0.150 \\
4 & -0.033 & -0.260 \\
5 & -0.067 & -0.370 \\
6 & -0.133 & -0.480 \\
7 & -0.200 & -0.590 \\
8 & -0.267 & -0.700 \\
9 & -0.333 & -0.810 \\
10 & -0.400 & -0.910 \\
11 & -0.467 & -1.000 \\
12 & -0.533 & - \\
13 & -0.600 & - \\
14 & -0.667 & - \\
15 & -0.733 & - \\
16 & -0.800 & - \\
17 & -0.867 & - \\
18 & -0.933 & - \\
19 & -0.967 & - \\
20 & -0.983 & - \\
21 & -1.000 & - \\
& & \\
& &
\end{tabular}

DBDB1, by bilinear interpolation of the depth data into the model grid. Before applying the interpolation, a certain amount of corrections (based on data taken from nautical maps) of the original data relative to the eastern Adriatic coast (Croatian Islands) was necessary, in order to improve the coastline definition and the bottom depth in the channels separating the islands. The minimum depth was set to $10 \mathrm{~m}$ for AIM and $3 \mathrm{~m}$ for NASM.

\subsection{AIM and NASM initial conditions}

Temperature and salinity initial conditions for the AIM simulations were obtained from the Artegiani et al. (1997a, b) data set updated with stations having bottom depths shallower than $15 \mathrm{~m}$. However, since this data set has no information south of the Otranto channel, in order to cover the Ionian sector of the model domain, we merged this data set with the temperature and salinity gridded $\left(0.25^{\circ}\right)$ monthly data available from the MED6 (Brankart and Pinardi, 2001) data set. The resulting data set was used to produce seasonal fields mapped on the AIM grid using objective analysis techniques as in Artegiani et al. (1997b) and Zavatarelli et al. (2002). Seasons were defined according to Artegiani et al. (1997a, b) as follows: winter, January to April; spring, May to June; summer, July to October; autumn, November to December. The winter fields were used as AIM initial condition.

The seasonal climatologies obtained are (obviously) very similar to those produced by Artegiani et al. (1997b) and Zavatarelli et al. (2002), and the reader is referred to such papers for a description of the fields.

The NASM initial temperature and salinity were obtained from the last year of integration of the AIM simulations. The
AIM results were averaged over 10 days and the averages corresponding to the first 10 January days of the perpetual year were interpolated in the NASM grid, in order to start the model in January.

\subsection{Surface and bottom boundary conditions}

AIM has been forced with monthly varying fields of surface heat, water and momentum (wind stress) fluxes. For the computation of the heat flux and wind stress monthly fields, the 6-h, 1.125, $1982-1993$ ECMWF surface re-analysis data (Gibson et al., 1997) and the COADS (da Silva et al., 1995) monthly cloud cover data were used. The sea surface temperature (SST) data needed for the surface flux computation were obtained from the Reynolds and Smith (1994) data set. See Korres and Lascaratos (2003) and Castellari et al. (1998) for a detailed description of the data and the bulk formulae used.

The wind stress $(\tau)$ is computed using the Hellerman and Rosenstein (1983) formula. As in Zavatarelli et al. (2002), the components of the wind stress (obtained through scalar averaging) were multiplied by a 1.5 factor following the indications of Cavaleri and Bertotti (1997). Monthly averages computed on the 1.125 grid were interpolated in the AIM and NASM grids.

The winter (Fig. 2a) and summer (Fig. 2b) averages of the wind stress over the AIM domain are shown in Fig. 2. The winter fields show the signature of the Bora wind from northeast affecting the whole basin. A general decrease in the wind stress characterizes the spring (not shown) and summer seasons, while the autumn field (not shown) indicates the occurrence of the Scirocco (SE) wind regime.

The computation of the total heat fluxes $(Q)$ at the air sea interface is given by:

$Q=Q_{s}-Q_{b}-Q_{h}-Q_{e}$.

The solar radiation $\left(Q_{S}\right)$ has been computed according to the Reed (1975) formula and the Reed (1977) parameterization. Clear sky radiation has been computed according to Rosati and Miyakoda (1988). The sea surface albedo was computed according to Payne (1972). The longwave radiation flux $\left(Q_{b}\right)$ was computed according to Bignami et al. (1995). The sensible $\left(Q_{h}\right)$ and latent $\left(Q_{e}\right)$ heat fluxes were computed according to classical formulas, with the turbulent exchange coefficients computed according to Kondo (1975).

The estimated annual heat budget for the AIM model domain is $-10 \mathrm{~W} / \mathrm{m}^{2}$. The seasonally averaged (winter and summer) surface heat flux fields for the AIM domain are shown in Fig. 3. They illustrate the strong heat losses affecting the whole basin in winter (Fig. 3a) and the heat gain in summer (Fig. 3b).

Following Zavatarelli et al. (2002), the heat flux was forced to produce sea surface temperatures consistent with the seasonal climatology (and avoiding excessive winter cooling resulting from the use of the uncorrected surface forcing), by adding a heat flux correction term to the surface 


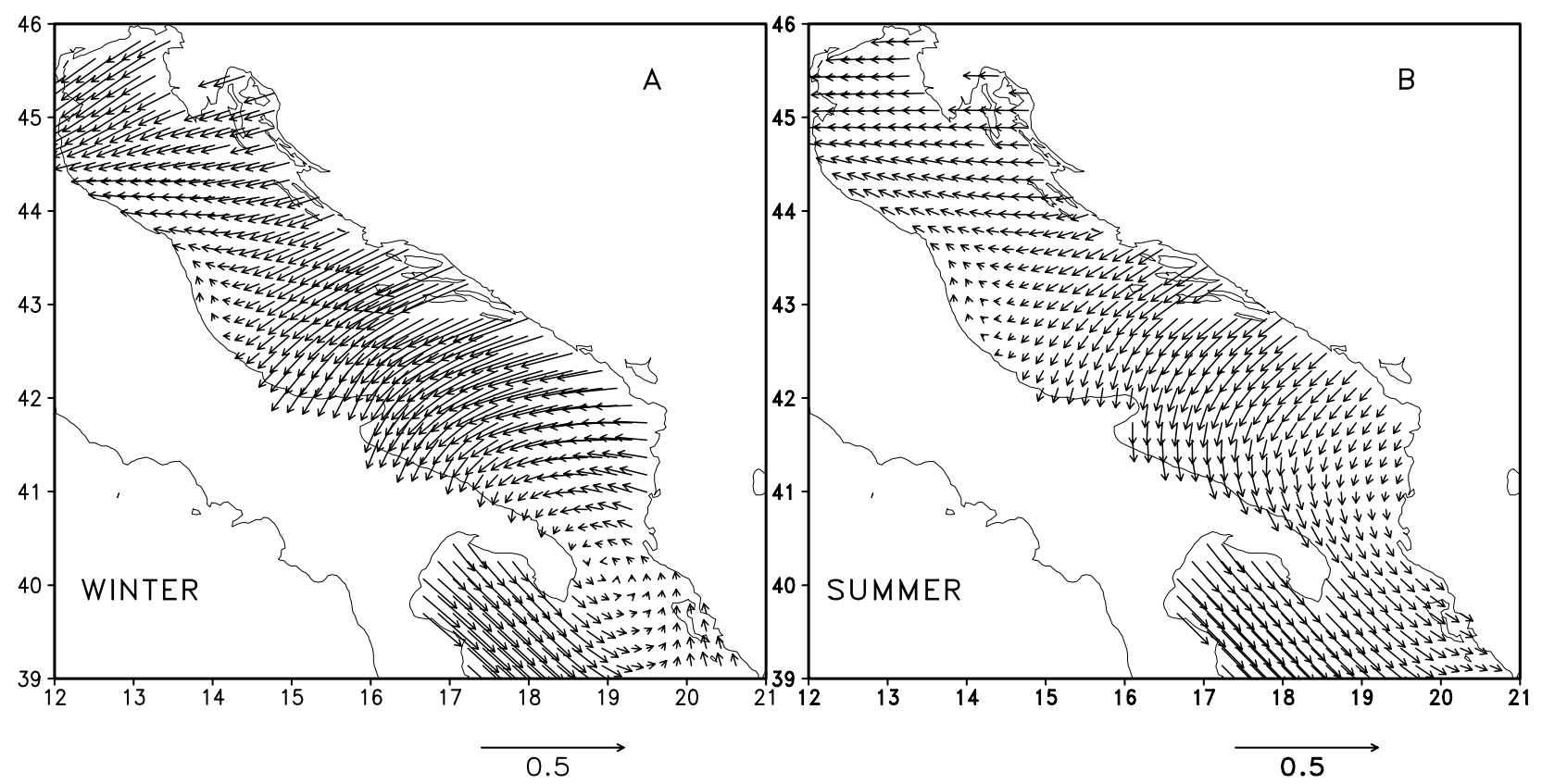

Fig. 2. Seasonal climatological wind stress distribution interpolated in the AIM grid. (A): winter, (B): summer. Units are dyne/ $\mathrm{cm}^{2}$. Not all grid points have been plotted. Seasons definition as in Artegiani et al. (1997a, b).

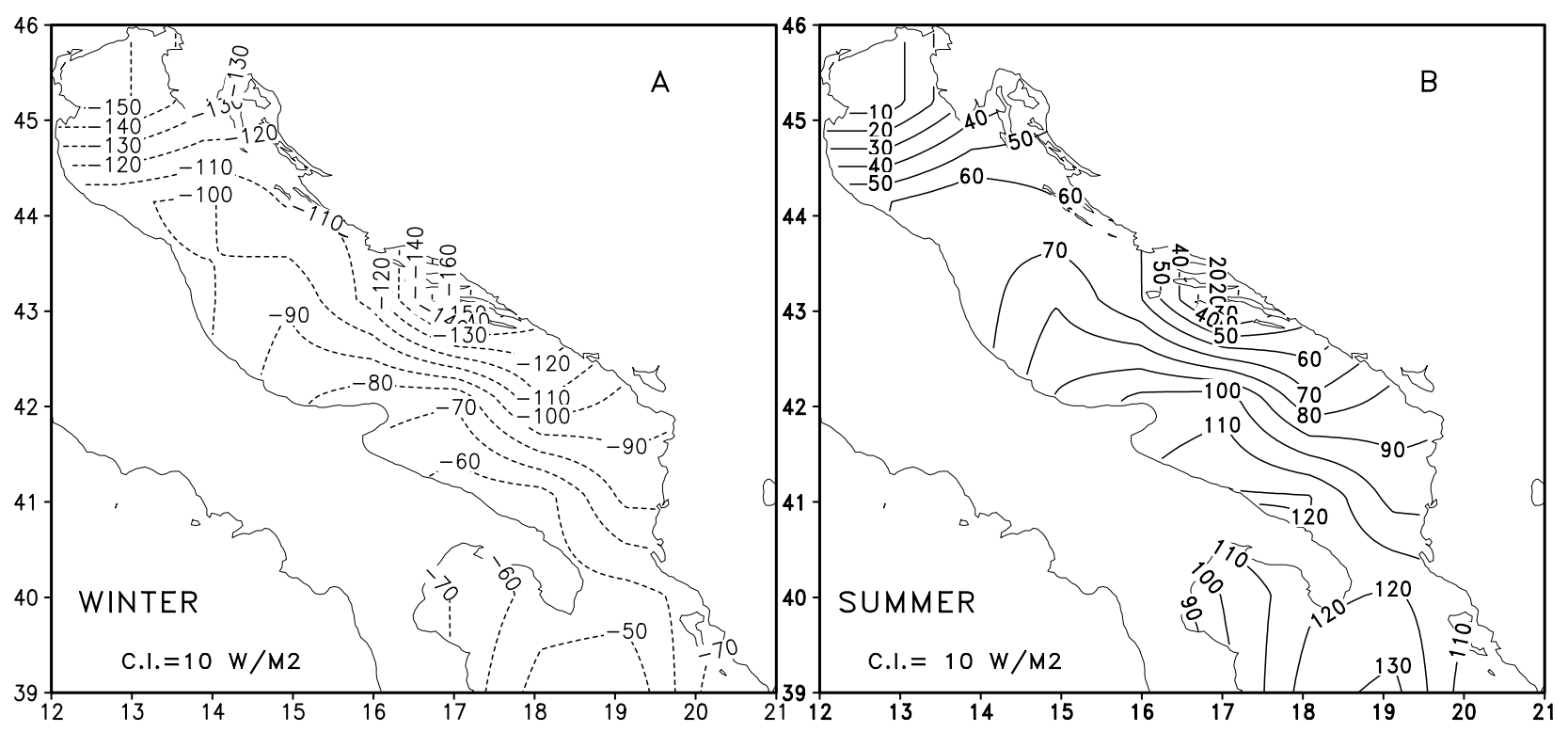

Fig. 3. Seasonal climatological surface heat flux interpolated in the AIM grid. (A): winter, (B): summer. Contour interval is $10 \mathrm{~W} / \mathrm{m}^{2}$. Seasons definition as in Artegiani et al. (1997a, b).

boundary condition for temperature, which took the following form:

$K_{H}\left(\frac{\partial T}{\partial z}\right)_{z=\eta}=\left(\rho_{0} C_{p}\right)^{-1}\left[(1-T r) Q_{s}-Q_{b}-Q_{h}-Q_{e}\right.$

$$
\left.+\left(\frac{\partial Q}{\partial T}\right)\left(T_{z=0}^{*}-T_{z=\eta}\right)\right]
$$

where $\operatorname{Tr}$ is the Jerlov (1976) transmission coefficient for a "clear" water type (listed in Table 2) and the last term in the above equation is the heat flux correction term, where $\partial Q / \partial T$ has been chosen to be $40 \mathrm{~W} / \mathrm{m}^{2}{ }^{\circ} \mathrm{C}$ (Oberhüber, 


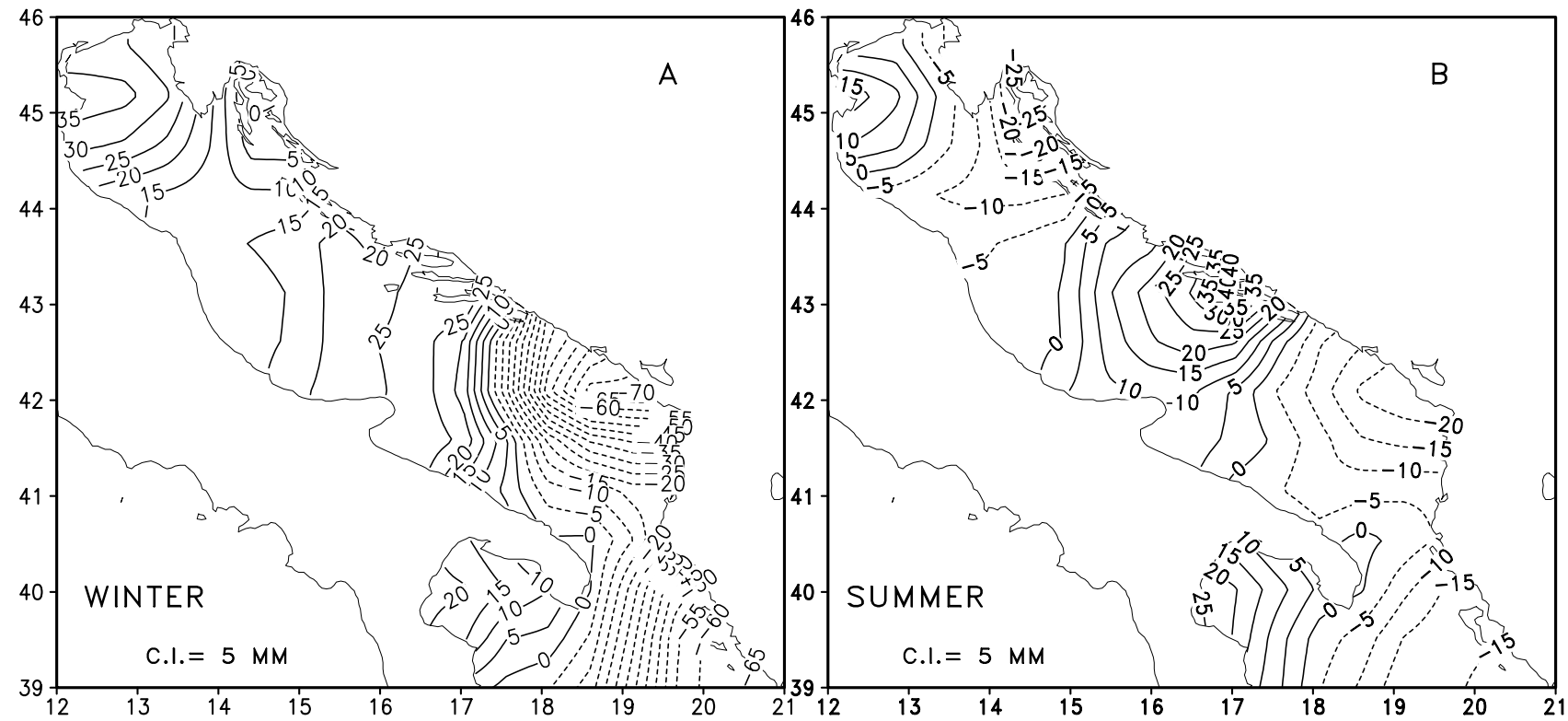

Fig. 4. Seasonal climatological (E-P) interpolated in the AIM grid. (A): winter, (B): summer. Contour interval is $5 \mathrm{~mm}$. Seasons definition as in Artegiani et al. (1997a, b).

1988), $T_{z=\eta}$ is the model predicted sea surface temperature and $T_{z=0}^{*}$ is the seasonally varying climatological sea surface temperature obtained from the objective mapping of the Artegiani et al. (1997b) and the MED6 data in the AIM grid. The remainder of the short-wave radiation heat flux $\left(Q_{S} T r\right)$ is propagated downward by adding the term $\partial R_{S} / \partial z$ to the model temperature conservation equation, where $R_{s}=Q_{s} \operatorname{Tr} e^{(\lambda z)}$ and $\lambda$ is the Jerlov (1976) "clear" water type attenuation coefficient (listed in Table 2).

The resulting annual heat budget obtained by the use of this heat flux correction was $-11 \mathrm{~W} / \mathrm{m}^{2}$.

The surface salinity flux:

$W_{s}=(E-P-R) S_{z=\eta}$,

is composed by the balance of Evaporation $(E)$, Precipitation $(P)$ and river runoff ( $R \neq 0$ at the "estuary" grid points only), while $S_{z=\eta}$ is the model predicted surface salinity field. In our simulations we do not consider a real water flux condition for both $E-P$ and $R$, since climatological fields force the model.

Monthly varying evaporation was computed from the $Q_{e}$ fields interpolated on the model grids. Monthly precipitation data were obtained by interpolation of the Legates and Wilmott (1990) global, $0.5^{\circ}$, monthly precipitation data set.

The seasonal (winter and summer) AIM fresh water budget due to $(E-P)$ only is shown in Fig. 4 and indicates that precipitation dominates over evaporation in the southern Adriatic (particularly in winter), while evaporative losses are prevailing in the middle and northern basins. The monthly river runoff data were obtained from the Raicich (1994; 1996) monthly climatology. Table 1 gives the annually averaged fresh water discharge for each of the Adriatic Rivers (the approximate location of the rivers mouth is shown in Fig. 1) considered in the present study. Table 1 also reports the Raicich (1994) estimate for the non-point runoff partitioned for the pertinent segments of the Adriatic coastline. Also, this fresh water source has been included in the fresh water forcing and has been considered as a distributed source function. On the contrary, the major Adriatic rivers listed in Table 1 were considered as point sources. Only the Po River runoff was distributed along more grid points, in order to represent the freshwater discharge of the various mouths of the delta. This mouth partitioning of the Po total runoff was defined according to the estimates reported in Provini et al. (1992).

Particular care was taken to ensure that the maximum rivers discharge $\left(R_{\max }\right)$ was never exceeding the "estuary" grid cell volume, i.e.:

$R_{\max } \leq \frac{\Delta x \Delta y \Delta \sigma_{1} H}{\Delta t_{i n t}}$,

where $\Delta \sigma_{1} H$ is the thickness of the surface "estuary" grid cell.

The AIM annual mean water budget obtained from the $(E-P-R)$ gives a gain of $1.20 \mathrm{~m} /$ year.

Also the salinity flux required a flux correction term, in order to impose a forcing that produces sea surface salinities consistent with the seasonal climatology and to avoid the excessive freshening of the basin resulting by the use of the climatological forcing. Therefore, the surface boundary condition for salinity took the form (Zavatarelli et al., 2002):

$K_{H}\left(\frac{\partial S}{\partial z}\right)=W_{s}+\Delta \sigma_{1} H / \gamma\left(S_{z=0}^{*}-S_{z=\eta}\right)$. 
The last term in the above equation is the salinity flux correction, where $S_{z=0}^{*}$ is the seasonally varying climatological surface salinity obtained with the same technique and the same data sets described for $T_{z=0}^{*}$ of Eq. (3). The relaxation time $\gamma$ has been chosen to be equal to 1 day.

The salinity flux forcing applied to NASM is identical to the AIM forcing. For the heat flux forcing we did not use the ECMWF derived fluxes; instead, we used the monthly averages diagnosed by the AIM simulations, i.e. the ECMWF derived heat flux monthly data corrected utilizing Eq. (3). The corrected monthly averages (yielding an annual heat budget over the NASM domain of $-12 \mathrm{~W} / \mathrm{m}^{2}$ ) were interpolated in the NASM grid, and a further heat flux correction was applied utilizing in Eq. (3), a $\partial Q / \partial T$ value of $20 \mathrm{~W} / \mathrm{m}^{2}{ }^{\circ} \mathrm{C}$.

All the monthly forcing fields $\left(Q, W_{s}, \tau\right)$ applied to AIM and NASM were linearly interpolated between adjacent months, assuming that the monthly mean average is applied to day 15 of the month. However, Killworth (1996) pointed out that this procedure does not conserve the monthly average value. To overcome this, Killworth (1996) proposed a simple procedure based on the computation of the so-called "pseudo values" whose linear interpolation preserves the correct average value. His technique was adopted in the present study. Seasonal $T_{z=0}^{*}$ and $S_{z=0}^{*}$ fields were instead kept seasonally constant and changed suddenly at the end of each season.

At the bottom, adiabatic boundary conditions are applied for temperature and salinity. For velocity, a quadratic bottom drag coefficient is computed utilizing a logarithmic drag law coefficient and the bottom roughness length listed in Table 2.

\subsection{Lateral open boundary conditions}

The three models constituting the Adriatic Sea Modelling System are hierarchically connected among each other by a simple off-line, one-way nesting technique.

The OGCM-AIM and the AIM-NASM nesting was designed in a way to ensure that the volume transport across the open boundary of the "nested" model matches the volume transport across the corresponding section of the "nesting" model, i.e.

$\int_{x_{2}}^{x_{1}} \int_{-H_{\text {nested }}}^{\eta_{\text {nested }}} V_{\text {nested }} d z d x=\int_{x_{2}}^{x_{1}} \int_{-H_{\text {nesting }}}^{\eta_{\text {nesting }}} V_{\text {orig }} d z d x$,

where $x_{1}, x_{2}$ are the extreme of the open boundary section, $\eta_{\text {nested }}, H_{\text {nested }}$ are the surface elevation and the bathymetry of the "nested" model at the boundary, respectively; $\eta_{\text {nesting }}, H_{\text {nesting }}$ are the surface elevation and the bathymetry of the "nesting" model at the boundary, respectively; $V_{\text {orig }}=V_{\text {orig }}(x, y, z, t)$ is the "nesting" model velocity normal to the boundary and $V_{\text {nested }}$ is the normal velocity field at the "nested" model open boundary. In the case of the AIM-OGCM nesting, the rigid lid characteristics of OGCM and the location of the AIM open boundary, cutting across two coastlines, ensures that the right-hand side of Eq. (5) is identically zero. Therefore, in this special case, Eq. (5) reduces to:

$\int_{x_{2}}^{x_{1}} \int_{-H_{\text {nested }}}^{\eta_{\text {nested }}} V_{\text {nested }} d z d x=0$.

In the case of the NASM-AIM nesting, the AIM transport across the NASM boundary was defined by computing the divergence of the total transport in the AIM region corresponding to the NASM model domain.

Let us define $V_{\text {int }}$ as the $V_{\text {orig }}$ interpolated on the nested open boundary. $V_{\text {nested }}$ will then contain $V_{\text {int }}$ and a correction to preserve the volume transport across the open boundary between AIM and NASM. Let us also define

$$
\begin{aligned}
& M_{\text {int }}=\int_{x_{2}}^{x_{1}} \int_{-H_{\text {nested }}}^{\eta_{\text {nested }}} V_{\text {int }} d z d x, \quad M_{\text {orig }}=\int_{x_{2}}^{x_{1}} \int_{-H_{\text {nesting }}}^{\eta_{\text {nesting }}} V_{\text {orig }} d z d x, \\
& \Delta M=M_{\text {int }}-M_{\text {orig }} \text { and } S=\int_{x_{2}}^{x_{1}} \int_{-H_{\text {nested }}}^{\eta_{\text {nested }}} d z d x .
\end{aligned}
$$

Therefore, the corrected velocity component normal to the boundary ( $\left.V_{\text {nested }}\right)$ is given by:

$V_{\text {nested }}(x, y, z, t)=V_{\text {int }}-\frac{\Delta M}{S}$.

This procedure ensures that the interpolation does not modify the net transport across the "nested" model open boundary.

The open boundary conditions used for the AIM-OGCM and the NASM-AIM nesting are:

1) For the total velocity,

$V_{\text {O.B. }}=V_{\text {nested }} ; \quad U_{\text {O.B. }}=U_{\text {int }}$,

where $V_{\text {O.B. }}$ and $U_{\text {O.B. }}$ are the normal and tangential velocity components on the open boundary, respectively, $U_{\text {int }}$ is the "nesting" model tangential velocity component $\eta$ interpolated on the "nested" model.

2) For the barotropic velocity component, defined as:

$\bar{V}=\frac{1}{H+\eta} \int_{-H}^{\eta} V d z$

we distinguish between the AIM-OGCM and the NASMAIM nesting.

At the AIM open boundary we impose (Zavatarelli et al., 2002),

$\bar{V}_{\text {O.B. }}=\bar{V}_{\text {nested }} \frac{H_{\text {nesting }}}{H_{\text {nested }}+\eta_{\text {nested }}} ; \quad \bar{U}_{\text {O.B. }}=\bar{U}_{\text {int }}$,

where $\bar{V}_{\text {O.B. }}, \bar{U}_{\text {O.B. }}$ are the normal and tangential barotropic velocity components on the open boundary, respectively, and $\bar{U}_{\text {int }}$ is the OGCM model tangential velocity component normal to the boundary interpolated on the AIM. The fractional term involving $H$ and the $\eta$ 's guarantees volume continuity. The NASM-AIM nesting involved the definition of an open 


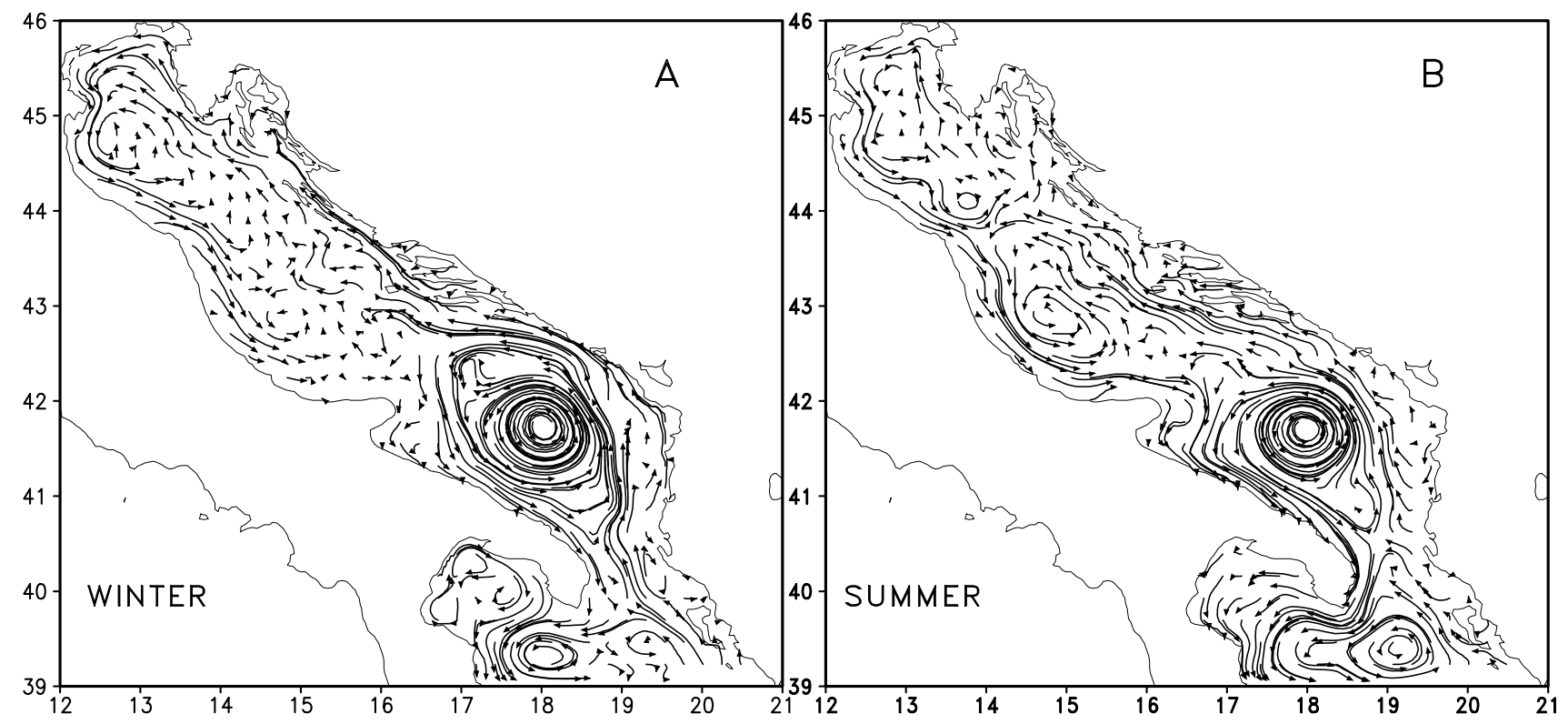

Fig. 5. Adriatic Intermediate Model (AIM). Seasonal velocity trajectories at $2 \mathrm{~m}$ depth computed as if the flow were steady for 5 days. (A): winter, (B): summer. Not all the grid points have been plotted. Seasons definition as in Artegiani et al. (1997a, b).

boundary condition for the barotropic velocity, accounting for differences in the surface elevation of the two models. The open boundary condition for barotropic velocity is a modified Flather (1976) formulation (see also Marchesiello et al., 2001) applied to the outflowing velocities:

$$
\begin{aligned}
\bar{V}_{\text {O.B. }} & =\left[\sqrt{\frac{g}{H_{\text {nested }}}}\left(\eta_{\text {nested }}-\eta_{\text {nesting }}\right)\right] \\
- & \bar{V}_{\text {nested }} \frac{H_{\text {nesting }}+\eta_{\text {nesting }}}{H_{\text {nested }}+\eta_{\text {nested }}}
\end{aligned}
$$

where $g$ is gravity.

On the inflow we imposed:

$\bar{V}_{\text {O.B. }}=\bar{V}_{\text {nested }}$.

Tangential velocities were imposed as in Eq. (8b).

Temperature and salinity on the open boundary outflow are locally upwinded:

$$
\begin{aligned}
& \frac{\partial T_{\text {O.B. }}}{\partial t}+V_{\text {O.B. }} \frac{\partial T_{\text {O.B. }}}{\partial y}=0 ; \\
& \frac{\partial S_{\text {O.B. }}}{\partial t}+V_{\text {O.B. }} \frac{\partial S_{\text {O.B. }}}{\partial y}=0
\end{aligned}
$$

while on the inflow they are prescribed from AIM data interpolated on the NASM open boundary ( $T_{\text {nesting }}$ and $\left.S_{\text {nesting }}\right)$ :

$T_{\text {O.B. }}=T_{\text {nesting }} ; \quad S_{\text {O.B. }}=S_{\text {nesting }}$.

The open boundary data were linearly interpolated between 10-day averages with the Killworth (1996) correction included.

\subsection{The numerical experiments}

Both AIM and NASM were integrated (under perpetual year forcing) for a total integration time of three years. AIM fields from the last year of integration were used to provide initial and open boundary conditions to the NASM. In the following, section simulation results are shown in terms of seasonal averages, where seasons are defined according to Artegiani et al. (1997a, b).

\section{Results and discussion}

\subsection{Adriatic Intermediate Model (AIM)}

The winter and summer near surface ( $2 \mathrm{~m}$ depth) velocity fields are shown in Fig. 5. Several of the circulation features described by Artegiani et al. (1997b) and Poulain (2001) can be recognized. The southern Adriatic is characterized at all seasons by a well-defined SAd gyre (stronger in winter). During winter (Fig. 5a), the gyre is clearly connected on its eastern side with the well-defined inflow of water from the Otranto Strait, forming the ESAC, and on its western side with the outflow of Adriatic waters constituted by the southern segment of the WACC. In summer (Fig. 5b), the Otranto inflow weakens due to recirculation along the eastern coast, as the summer surface elevation field (not shown) indicates for that region a narrow and elongated anticyclonic gyre. On the contrary, the outflow on the western side of the basin persists. It has to be noted that the inflow/outflow exchanges at the Otranto Strait appear much better represented here than 


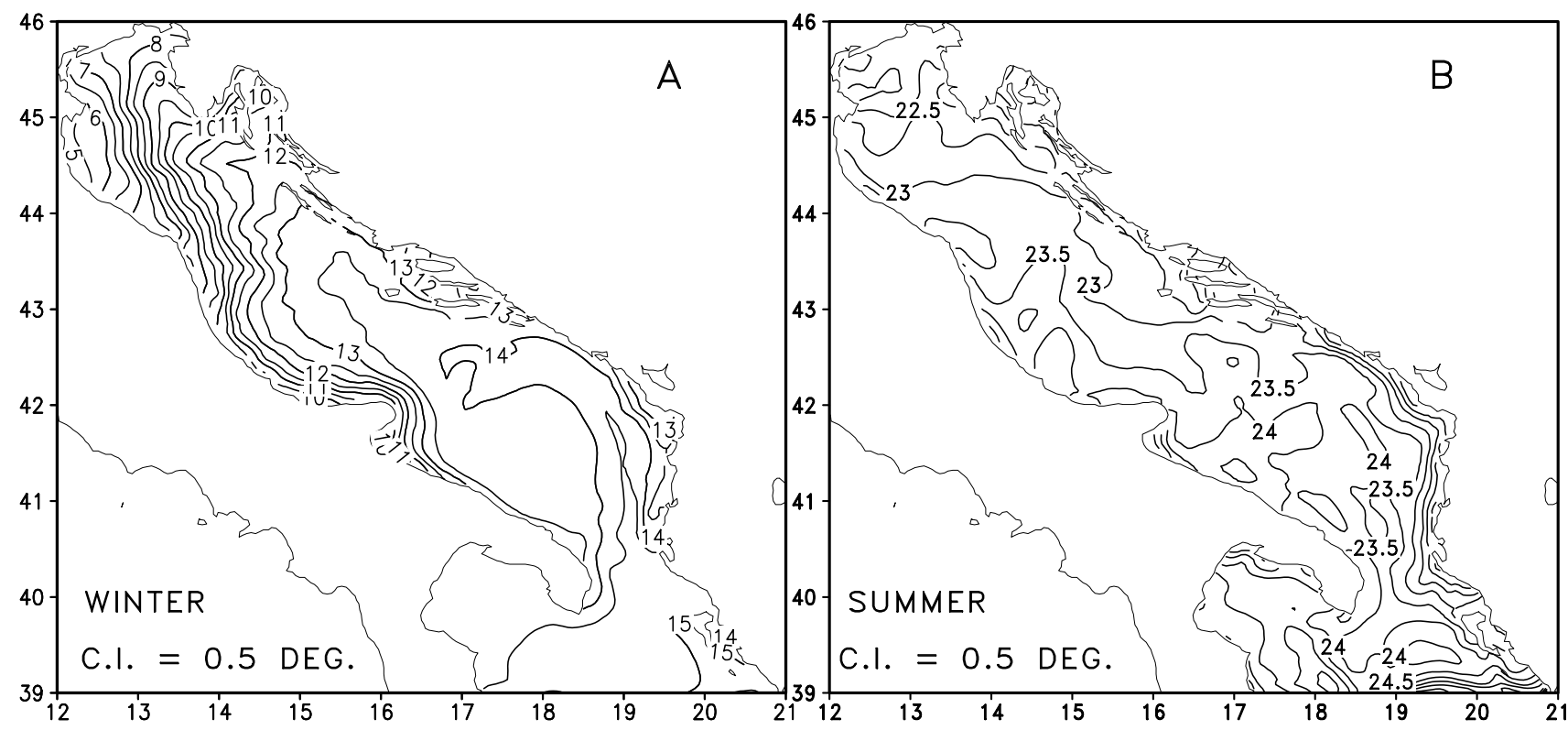

Fig. 6. Adriatic Intermediate Model (AIM). Seasonal surface temperature fields. (A): winter, (B): summer. Contour interval is $0.5^{\circ}$. Seasons definition as in Artegiani et al. (1997a, b).

in the previous modelling effort of Zavatarelli et al. (2002), probably due to the higher resolution of the grid here.

In the middle Adriatic, the MAd cyclonic gyre reinforces (in agreement with observations) from winter to summer. The ESAC is present in both seasons, but with different characteristics: in winter it is narrow, close to the coast, and part of the flow goes between the eastern mainland and the Dalmatian Islands, while in summer it is broader and constitutes the eastern side of the MAd cyclonic gyre.

The WACC is present at all seasons, extending from the northern Adriatic to the Otranto Strait, but during winter (Fig. 5a) it weakens in the middle Adriatic, part of the flow being deflected into the (weak) MAd cyclonic gyre. The lagrangian observations of Poulain (2001) and the previous modelling of Zavatarelli et al. (2002) are indicating, for the summer season, the WACC detachment from the coast with the formation of meanders. The present simulation reproduces such features, but the tendency to form meanders appears more limited in space with respect to the previous simulations. Moreover, it has to be stressed that the circulation field shown in Fig. 5b is a seasonal average and the averaging procedure smooths out strongly the smaller scale space and time variability. We return to the issue of the smaller scale variability in Sect. 3.2, where the AIM and NASM simulations will be compared and discussed.

In the northern Adriatic the model gives at all seasons a circulation characterized by the NAd cyclonic gyre that, however, during summer, is located south of its winter position.

The seasonal surface temperature and salinity fields corresponding to the velocity fields of Fig. 5 are shown in Figs. 6 and 7 , respectively. The simulated surface temperature indicates, for the winter season (Fig. 8a), a good agreement with the observed climatology. The model reproduces the cold surface temperature affecting the whole northern Adriatic basin and the western coastal region where cooler temperatures are matching the extension of the WACC, giving rise, as discussed by Artegiani et al. (1997b) and Zavatarelli et al. (2002), to density compensation processes. In the southern Adriatic, during winter (Fig. 6a), the inflow of water from the Ionian Sea is clearly represented as a tongue of relatively warm water along the eastern coast. In summer (Fig. 6b), the surface temperature fields appear less structured than the winter one. Artegiani et al. (1997b) ascribed the summer small-scale surface temperature distribution to mesoscale processes. The model partially reproduces this small-scale variability, as the spatial resolution $(5 \mathrm{~km})$ is probably not sufficient to entirely capture the mesoscale dynamics. In the southern Adriatic, along the eastern coast, the model indicated the occurrence of coastal upwellings (Fig. 6b). Observational evidence for that region is scanty, but remote sensing and drifter observations seem to confirm the occurrence of such coastal upwellings (Vogt, 1999, as quoted by Poulain and Cushman-Roisin, 2001).

It has to be noted that in summer, in the region of the model domain in proximity to the open boundary, the model produces a band of warmer water parallel to the open boundary. This is not due to the ineffectiveness of the OGCM to AIM coupling, but to inconsistencies between the OGCM surface temperature values (specified on the open boundary) and the AIM predicted temperatures. This has been found to be probably determined by the lack of solar radiation penetration in 


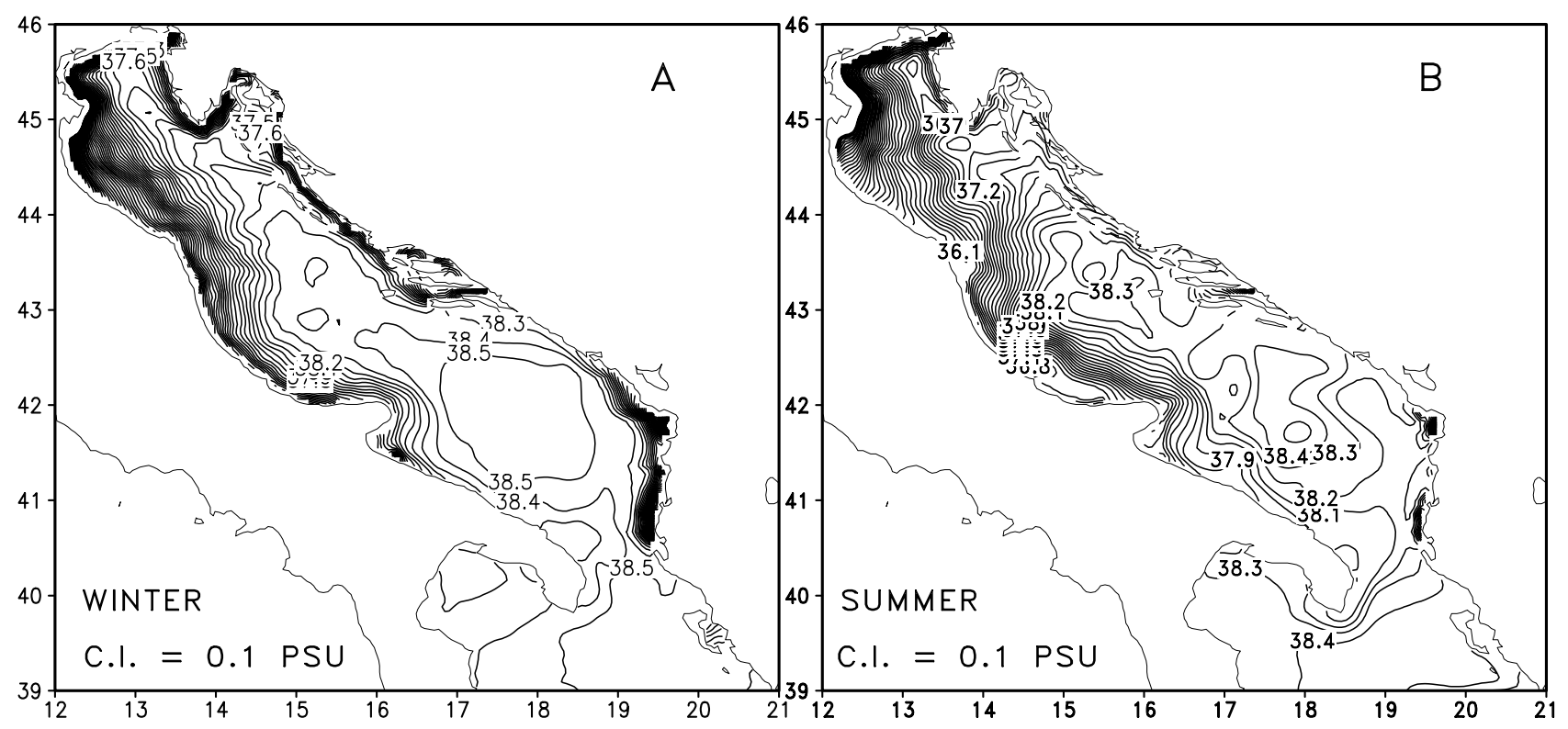

Fig. 7. Adriatic Intermediate Model (AIM). Seasonal surface salinity fields. (A): winter, (B): summer. Contour interval is 0.1 psu. Seasons definition as in Artegiani et al. (1997a, b).

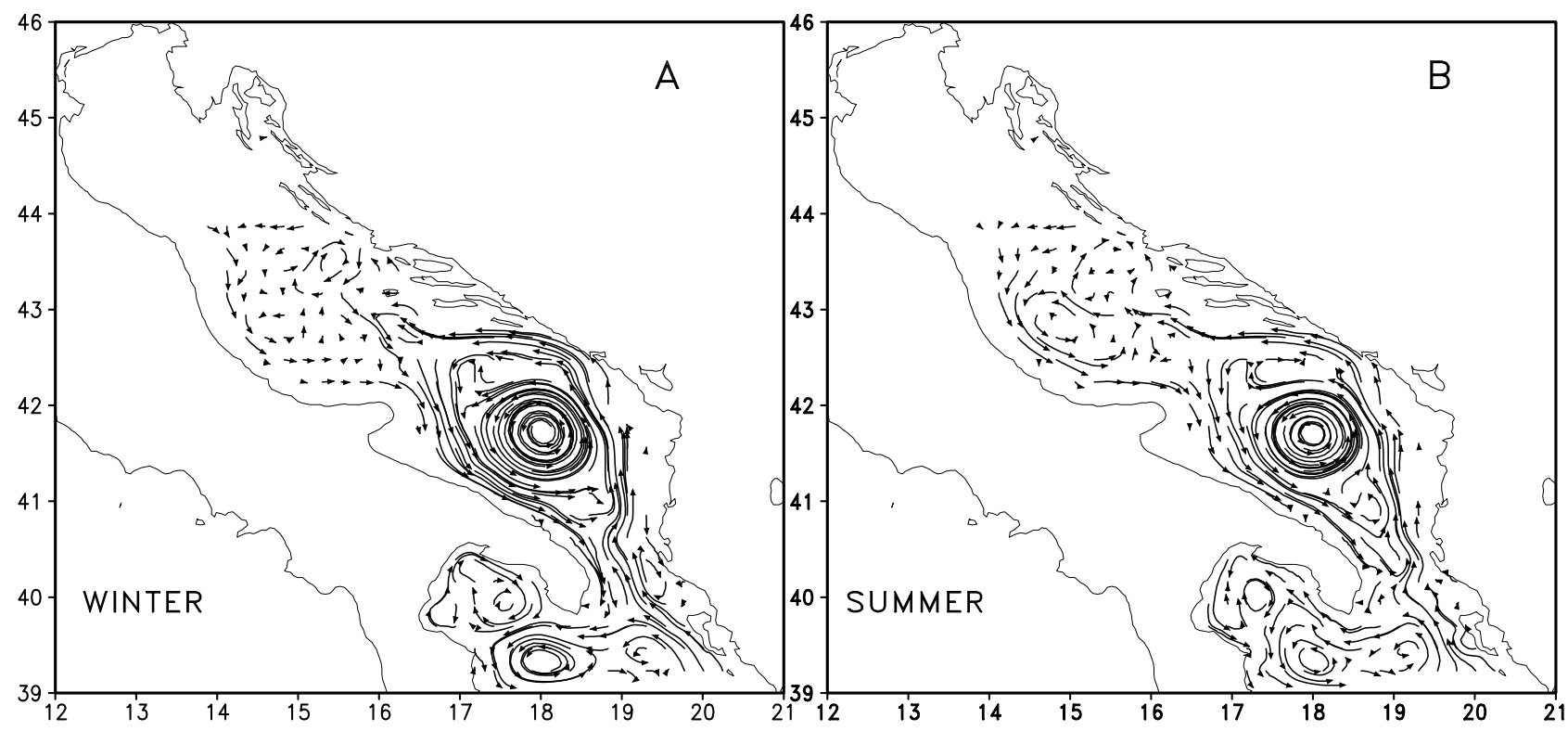

Fig. 8. Adriatic Intermediate Model (AIM). Seasonal velocity trajectories at $75 \mathrm{~m}$ depth computed as if the flow were steady for 10 days. (A): winter, (B): summer. Not all the grid points have been plotted. Seasons definition as in Artegiani et al. (1997a, b).

the OGCM that seems to produce systematically higher surface temperatures with respect to the AIM, that makes use of the solar radiation penetration.

The salinity seasonal surface fields (Fig. 7) also indicate that the model is correctly representing the surface features observable in the seasonal climatologies. In both winter (Fig. 7a) and summer (Fig. 7b) the rivers' freshwater discharge along the western coast of the northern Adriatic and the evaporative losses in the offshore regions determine low coastal salinity values and a marked coastal to offshore gradient marking the WACC extension. Maximum salinity values are observed in both seasons in the regions of the MAd and SAd cyclonic gyres. This is also consistent with the observed climatology, although the simulated surface salinities are, in general, slightly lower than the corresponding observations. From winter to summer the coast to offshore salinity gradi- 


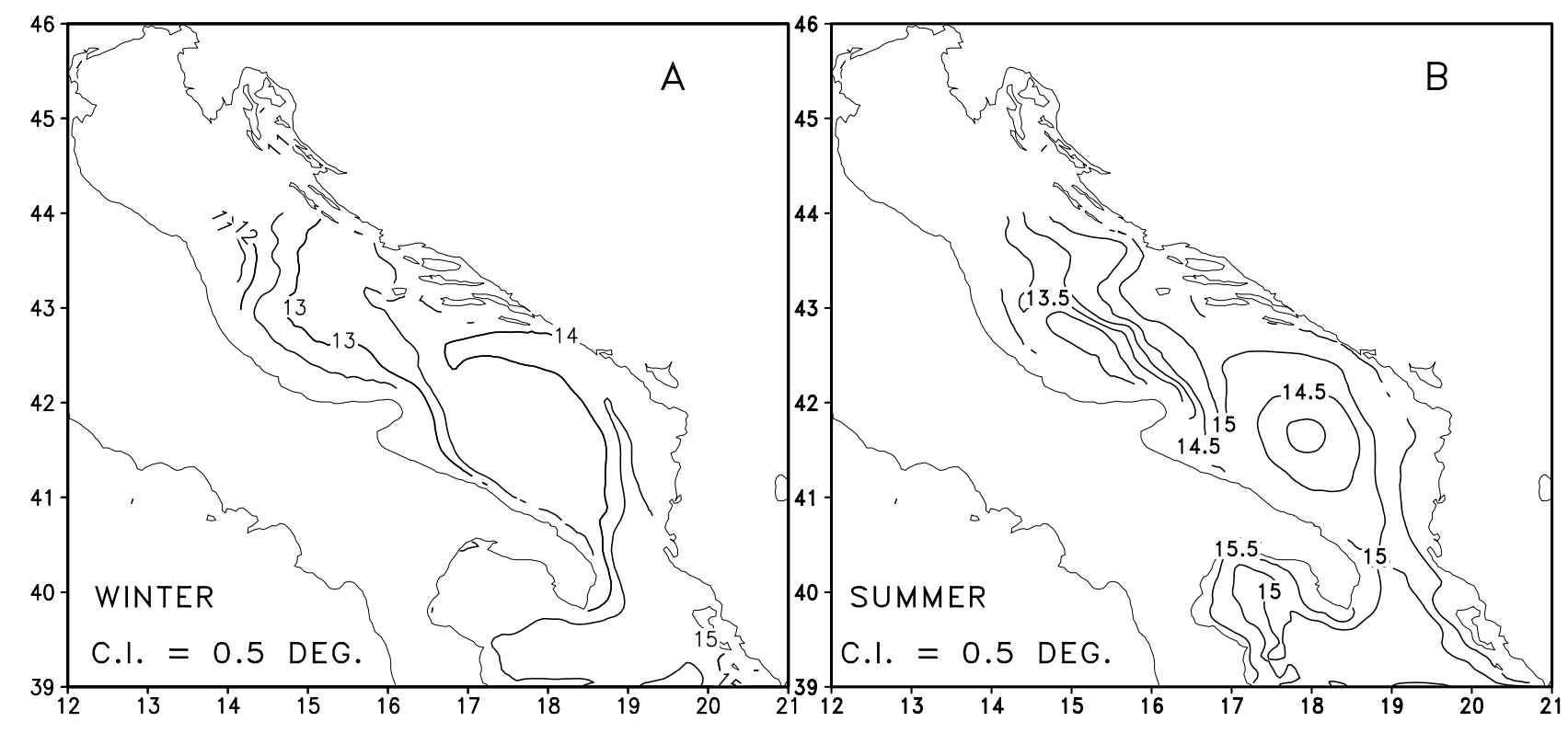

Fig. 9. Adriatic Intermediate Model (AIM). Seasonal temperature fields at $75 \mathrm{~m}$ depth. (A): winter, (B): summer. Contour interval is $0.5^{\circ}$. Seasons definition as in Artegiani et al. (1997a, b).

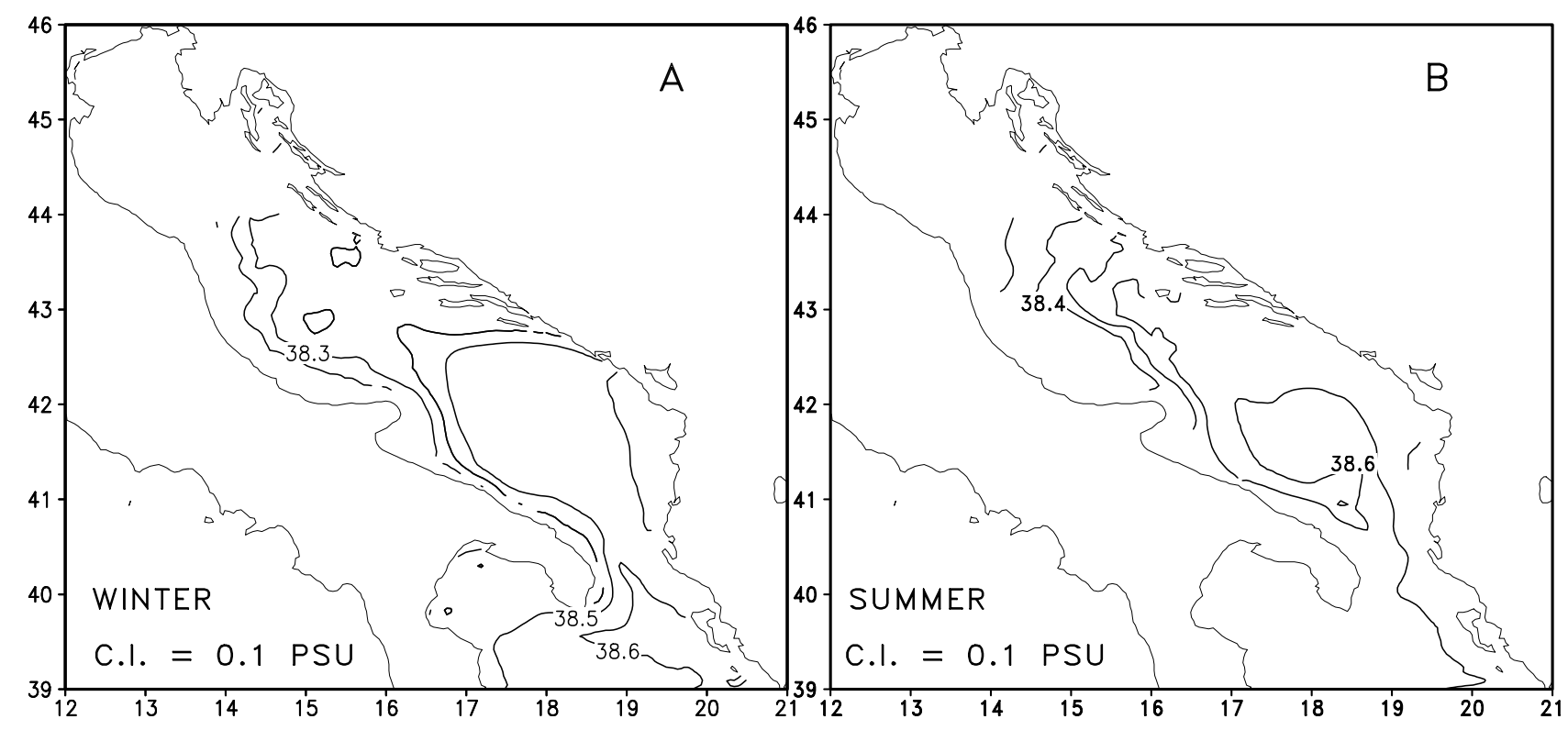

Fig. 10. Adriatic Intermediate Model (AIM). Seasonal salinity fields at $75 \mathrm{~m}$ depth. (A): winter, (B): summer. Contour interval is $0.1 \mathrm{psu}$. Seasons definition as in Artegiani et al. (1997a, b).

ent weakens in the northern Adriatic. This is a well-known feature of the Adriatic Sea phenomenology (Artegiani et al., 1997b). The summer freshening of the whole northern Adriatic occurs despite the fact that during that season river discharge is at minimum, but the generalized wind weakening all over the basin (Fig. 2b) allows for an enhanced offshore spreading of the Po River fresh water discharge that affects the whole sub-basin and not only the western coastal regions.
At $75 \mathrm{~m}$ depth, the seasonal circulation (Fig. 8) is also characterized by the presence of the SAd and MAd cyclonic gyres. Also, at this depth, the SAd gyre is stronger in winter than in summer. In winter (Fig. 8a) the SAd gyre is connected with the inflow/outflow currents of the Otranto Strait. The seasonal evolution of the Otranto Strait inflow/outflow is different than at surface, as at this depth in summer (Fig. 8b), the inflow (although weaker with respect to winter) per- 


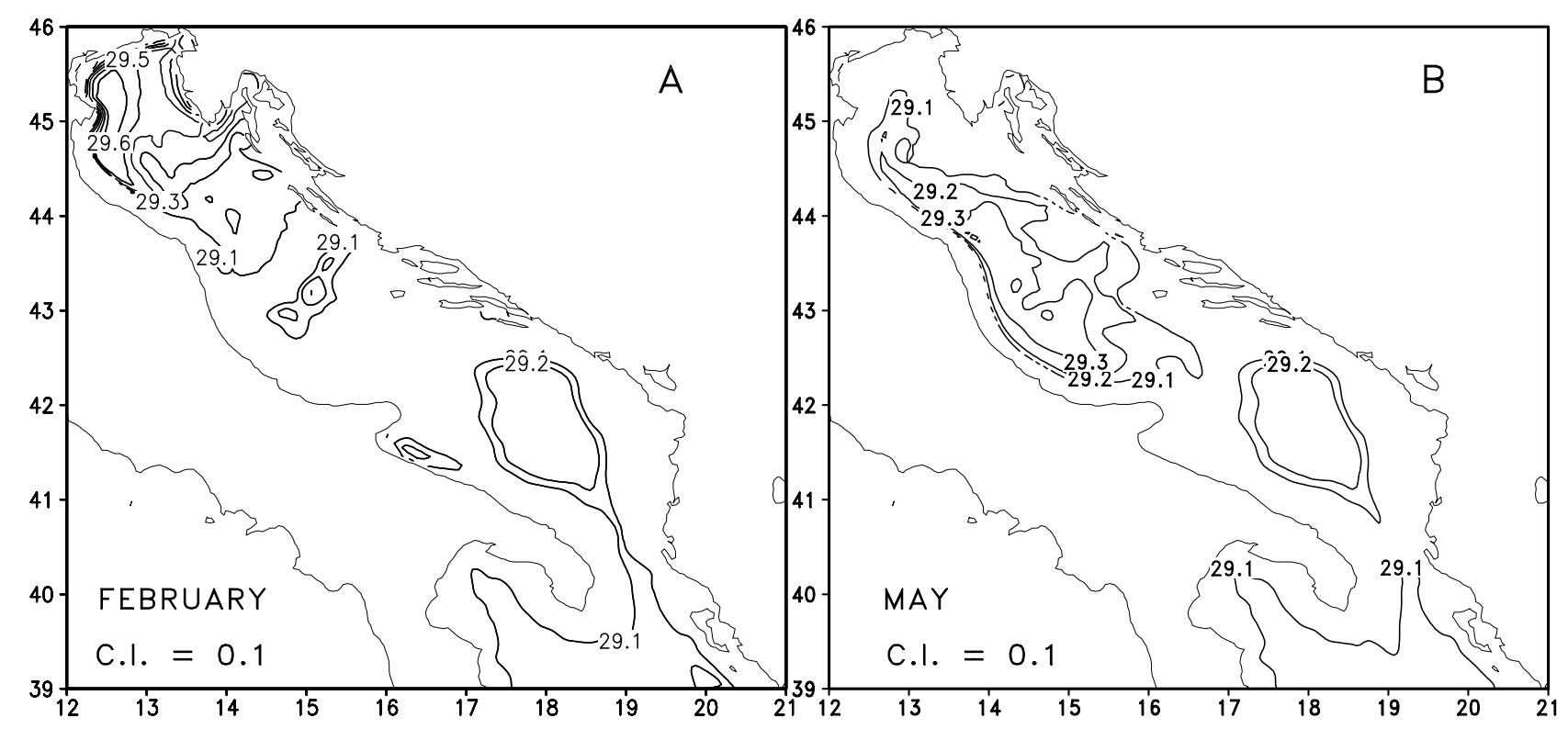

Fig. 11. Adriatic Intermediate Model (AIM). Bottom $\sigma_{\theta}$ distribution. (A): February, (B): May. Contour interval is $0.1 \mathrm{~kg} / \mathrm{m}^{3}$. For clarity, $\sigma_{\theta}$ values lower than $29.1 \mathrm{~kg} / \mathrm{m}^{3}$ have been masked out.

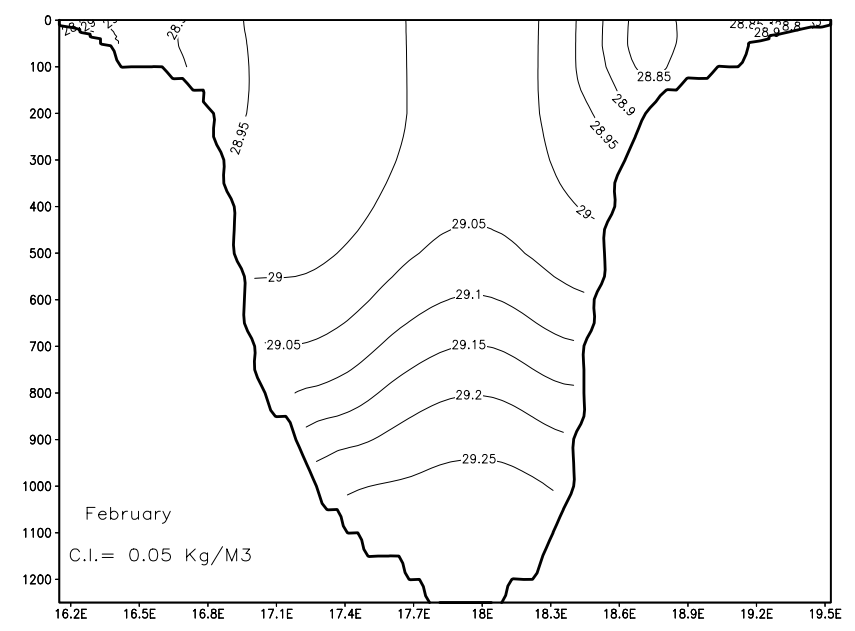

Fig. 12. Adriatic Intermediate Model (AIM). $\sigma_{\theta}$ distribution in February along the zonal section A of Fig. 1. Contour interval is $0.05 \mathrm{~kg} / \mathrm{m}^{3}$.

sists, while the outflow appears to be largely recirculating into the SAd gyre. In the central Adriatic, the winter MAd gyre (Fig. 8a) appears very weak and disconnected from the southern Adriatic circulation, while in summer the two gyres (MAd and SAd) are connected by both the northward current on the eastern side and the southward current on the western side of the basin. This pattern is in relative agreement with the dynamic height computations of Artegiani et al. (1997b) that indicate a stronger interconnection between the two gyres in summer-autumn rather than in winter. Interestingly, during winter the cyclonic circulation in the central
Adriatic is connected with a southward flowing vein of water originating from the north that almost disappears in summer. The analysis of the corresponding temperature and salinity fields indicates (see below) that this current is caused by the southward spreading of the dense water mass formed in winter over the northern Adriatic shelf.

The $75 \mathrm{~m}$ depth temperature and salinity fields for winter and summer are shown in Figs. 9 and 10, respectively. It can be noted that the winter vein of water coming from the north and interacting with the MAd gyre is characterized by temperature values lower than $12.0^{\circ}$ (Fig. 9a) and by salinity values lower than 38.2 psu (Fig. 10a). These are values in good agreement with the definition of the northern Adriatic dense water mass given by Artegiani et al. (1997a). Therefore, it appears that the AIM is correctly representing the dense water formation in the northern Adriatic. We shall return later to this feature by illustrating the distribution of bottom $\sigma_{\theta}$. The other notable feature appearing in the temperature and salinity distribution is the higher temperature and salinity signature of the inflow from the Otranto Strait and its entrainment into the southern Adriatic cyclonic circulation.

As stated above, the model seems to represent correctly the winter dense water formation over the northern Adriatic shelf. A confirmation of this comes from the examination of the bottom $\sigma_{\theta}$ distribution in February and May, as shown in Fig. 11. In February (Fig. 12a), bottom water with $\sigma_{\theta}$ values ranging from 29.3 to $29.6 \mathrm{~kg} / \mathrm{m}^{3}$ can be observed over the northern Adriatic shelf, offshore of the Po delta. The location of the dense water patch location is consistent with the observations of Franco (1972). Analysis of the bottom velocity field (not shown) indicates, in that region, a south- 

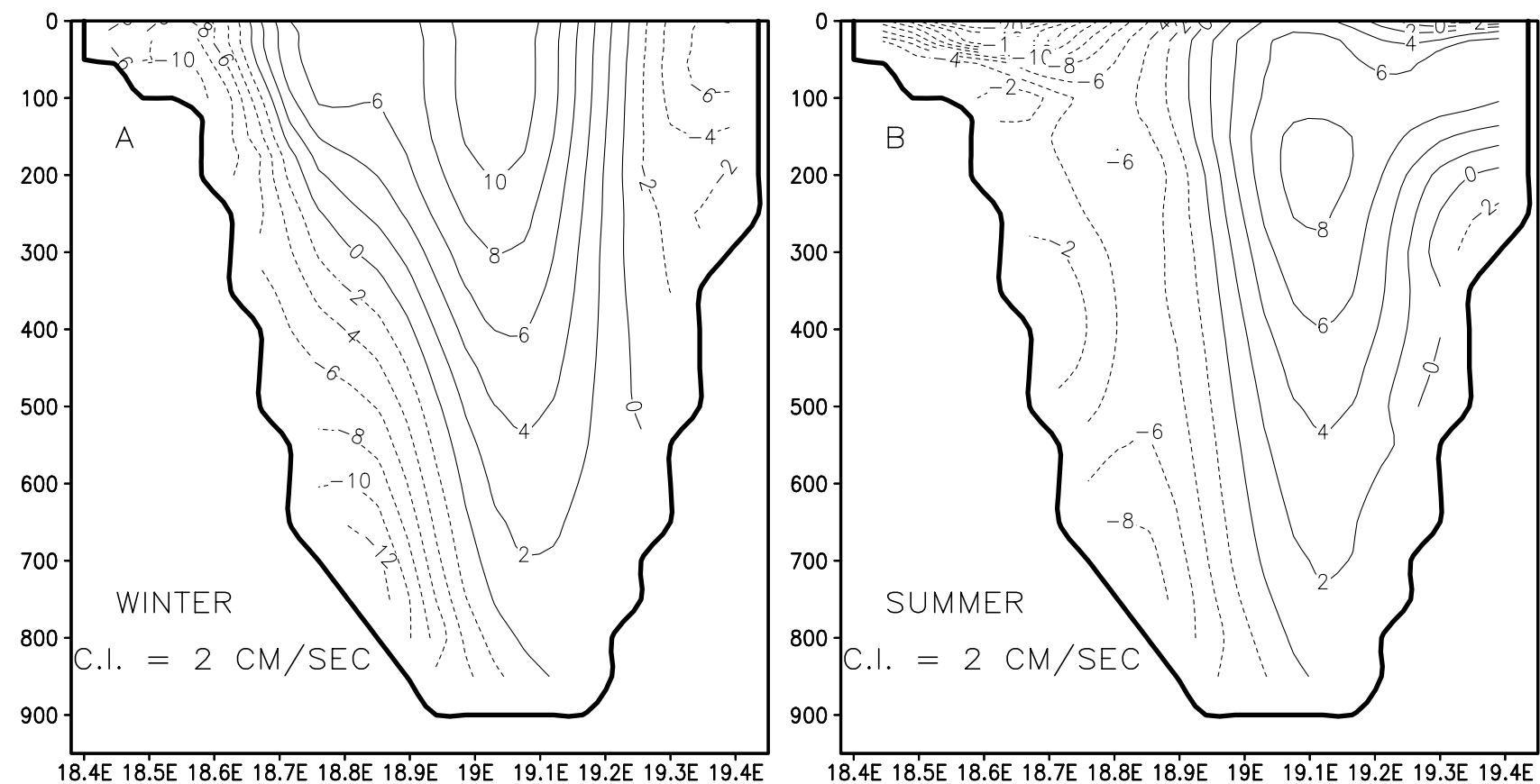

Fig. 13. Adriatic Intermediate Model (AIM). Seasonally averaged meridional velocity sections in the Strait of Otranto (zonal section B of Fig. 1). (A): winter, (B): summer. Contour interval is $1 \mathrm{~cm} / \mathrm{s}$. Positive values denote northward flow. Seasons definition as in Artegiani et al. (1997a, b).

Table 4. Estimates of the southward transport (Sv) in the Otranto Channel from Gacic et al. (1999) and from the AIM simulation

\begin{tabular}{ccc}
\hline $\begin{array}{c}\text { Southward transport in } \\
\text { the Otranto Strait (Sv) }\end{array}$ & Winter & Summer \\
\hline Gacic et al. (1999) & 1.40 & 0.71 \\
\hline AIM & 1.36 & 1.27 \\
\hline
\end{tabular}

ward displacement. Dense water having a lower $\sigma_{\theta}$ value $\left(29.2 \mathrm{~kg} / \mathrm{m}^{3}\right)$ is also located in the Pomo depressions. In May (Fig. 11b), no dense water can be observed over the northern Adriatic shelf and the dense water mass is now located in the middle Adriatic, where the Pomo depressions are now filled with water having $\sigma_{\theta}$ values higher than $29.3 \mathrm{~kg} / \mathrm{m}^{3}$. The plot relative to the month of May is also indicating displacement along the bottom of the dense water mass toward the deep southern Adriatic. We can, therefore, conclude that the AIM is successfully representing the dense water formation process in the northern Adriatic, as well as its spreading into the middle Adriatic and the associated bottom water renewal in the Pomo Depressions, as described by Franco and Bregant (1980).

In the southern Adriatic the model is also reproducing the convective process leading to dense water formation. The February $\sigma_{\theta}$ distribution along the zonal section A of Fig. 1
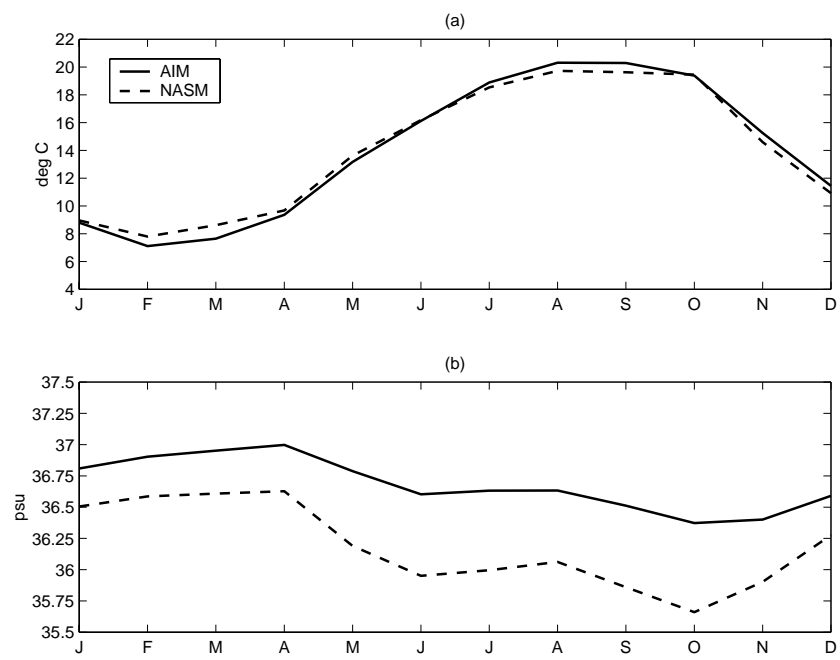

Fig. 14. Annual cycle of the basin averaged NASM temperature and salinity compared with the average computed over the AIM model domain sector corresponding to the NASM domain. Solid line: AIM, dashed line: NASM. (a): Temperature; (b): Salinity. Units are ${ }^{\circ} \mathrm{C}$ for temperature and psu for salinity.

is shown in Fig. 12. The plot shows the doming of the isopycnals determined by the upwelling associated with the southern Adriatic cyclonic circulation described above, and the vertical homogenization of the water column from the surface to the depth of about $500 \mathrm{~m}$, with $\sigma_{\theta}$ values ranging 

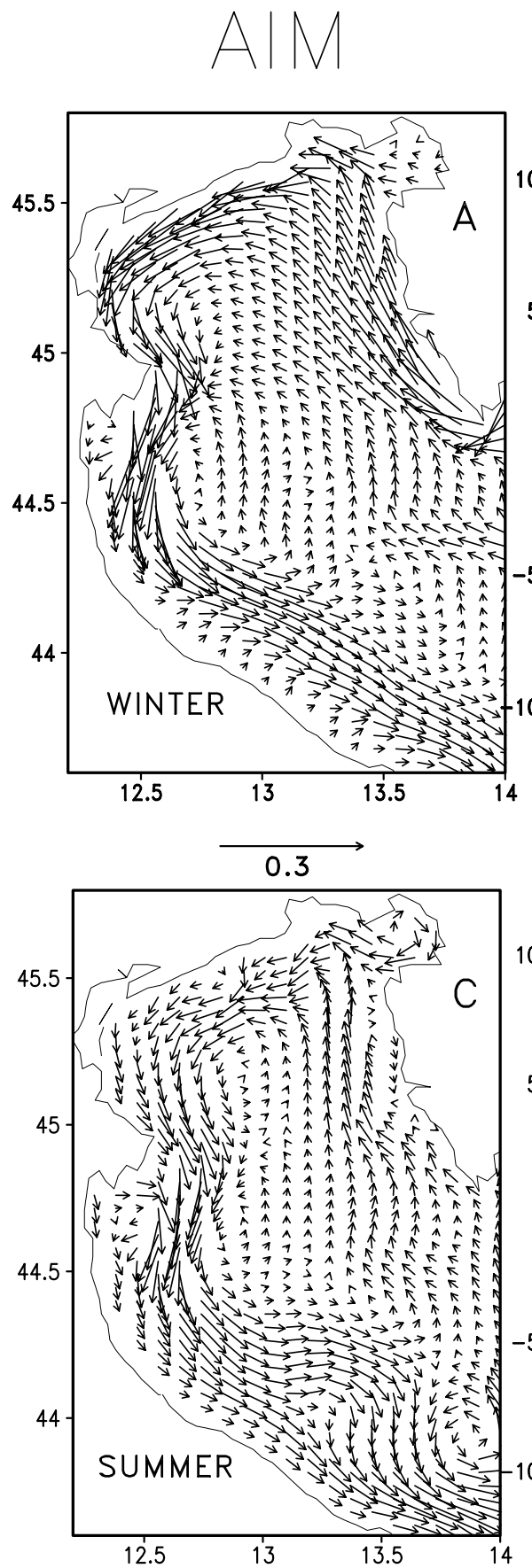
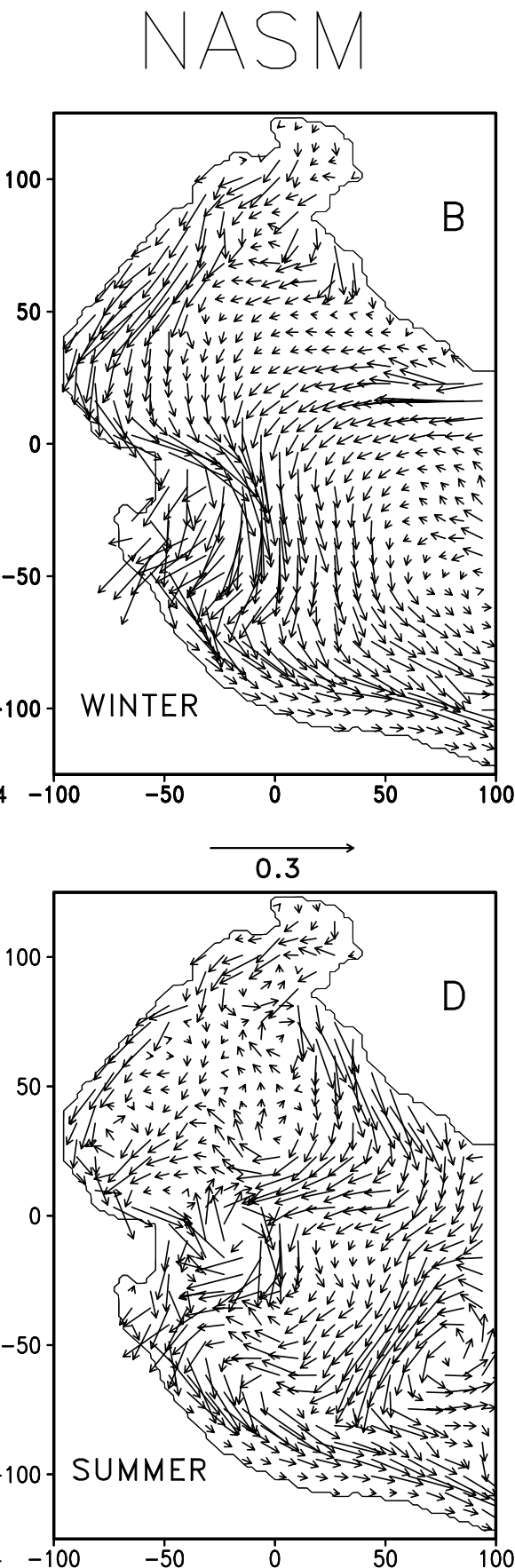

Fig. 15. Northern Adriatic Shelf Model (NASM) $2 \mathrm{~m}$ depth seasonal (winter and summer) circulation compared with the corresponding AIM simulation. (A): AIM winter, (B): NASM winter, (C): AIM summer, (D): NASM summer. Units are $\mathrm{m} / \mathrm{s}$. Not all grid points are plotted. Seasons definition as in Artegiani et al. (1997a). between 29.0 and $29.1 \mathrm{~kg} / \mathrm{m}^{3}$. The breaking of the vertical stratification in the upper layers occurs in February, persists (weakly) in March, and in April the water column appears again to be density stratified. However, the $\sigma_{\theta}$ values simulated by the model appear lower than the values reported by Ovchinnikov et al. (1987) for a dense water formation event in the southern Adriatic.

We end our analysis of the AIM results by showing, in Fig. 13, seasonally averaged sections of the meridional velocity in the Strait of Otranto (along zonal section B of
Fig. 1). Recent measurements of the current system in the Otranto Strait (Gacic et al., 1999; Kovacevic et al., 1999) indicate a flow structure characterized by inflow on the eastern side of the strait, and outflow on the western side. The AIM simulation indicates for winter and summer a good agreement with the flow structure described above, as the outflow is located primarily on the western side and in the deep part of the Strait, while the inflow is located mainly on the eastern side. Gacic et al. (1999) estimates of the winter and summer southward transport across the strait are given in Table 4, 

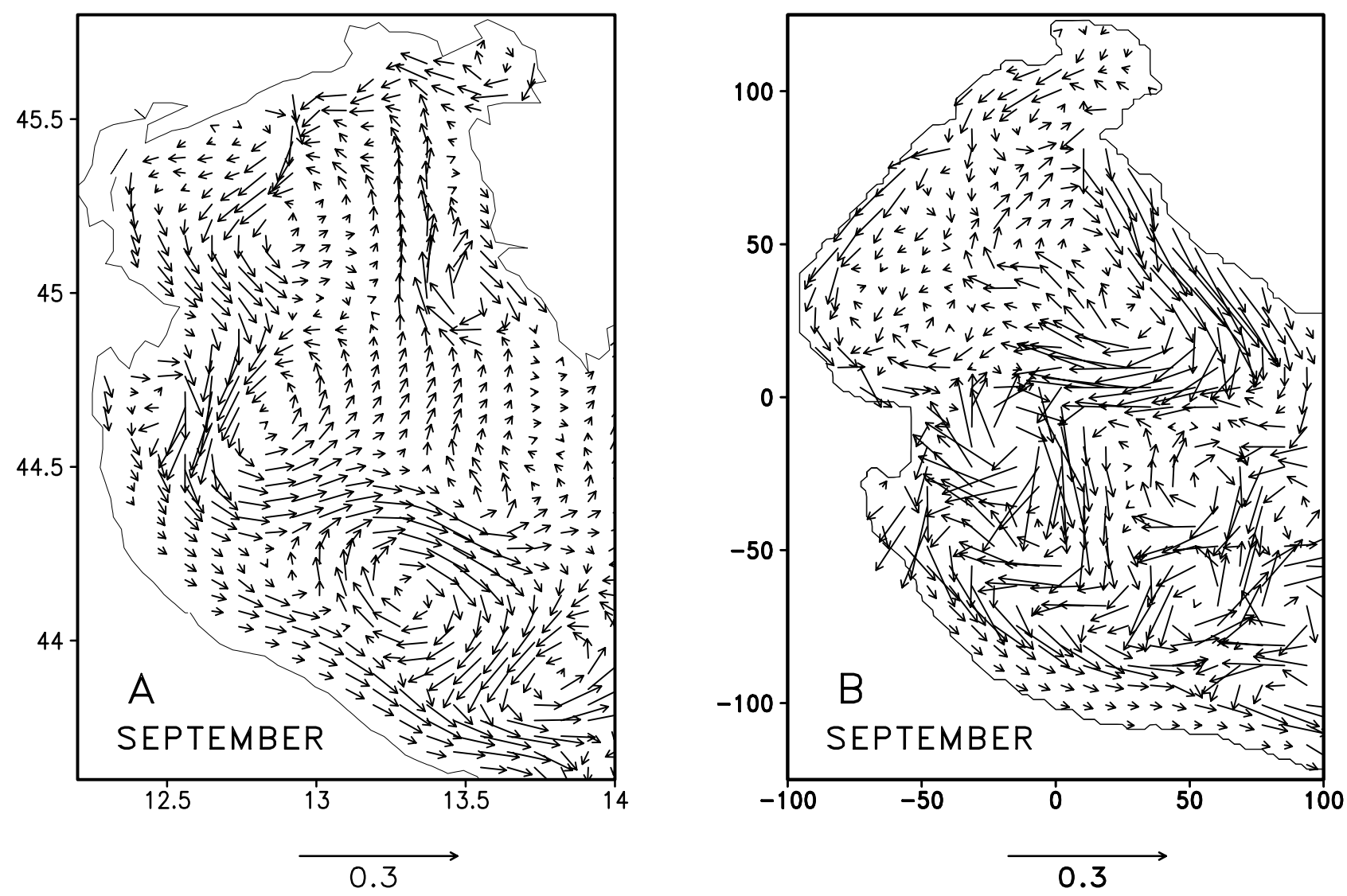

Fig. 16. Northern Adriatic Shelf Model (NASM) $2 \mathrm{~m}$ depth September circulation compared with the corresponding AIM simulation. (A): AIM, (B): NASM. Units are $\mathrm{m} / \mathrm{s}$. Not all grid points are plotted.

along with the corresponding estimates arising from the AIM simulation. It can be noted that the winter value is in good agreement with the Gacic et al. (1999) estimate, while the summer value appears larger than the corresponding estimate based on the observations.

\subsection{Northern Adriatic Shelf Model (NASM)}

We describe now the model simulations of the Northern Adriatic circulation obtained with NASM, in terms of basin averaged temperature and salinity annual cycle and of surface property distribution, compared with the corresponding AIM simulations. A comparison between the basin averaged NASM temperature and salinity and the corresponding AIM sector of the model domain is shown in Fig. 14. It can be seen that the temperature annual cycles simulated by the two models are in tight agreement (Fig. 14a). The salinity annual cycles (Fig. 14b), on the contrary, shows only a qualitative agreement, since the general trends are comparable, but the NASM basin averaged salinity appears systematically lower than the AIM averages. A possible explanation of this difference is given below in terms of the differences in the circulation patterns simulated by the two models.
The winter and summer NASM surface ( $2 \mathrm{~m}$ depth) circulation (along with the corresponding AIM simulation) is shown in Fig. 15. During winter, NASM (Fig. 15b) reproduces the inflow of water from the south along the eastern coast. However, the inflow appears weaker than the corresponding AIM feature and deflected toward the center of the basin due to the development of an anticyclonic structure located along the northern coast of the Istrian peninsula. The outflow on the western coast is defined by a strong and narrower (with respect to AIM, Fig. 15a) WACC current, particularly intense in the Po River delta region. In summer, on the contrary, the two models produce a rather different circulation pattern. The anticyclonic structure appearing in the NASM simulation during winter offshore of the Istrian coast extends south in the transition from winter to summer, to form an anticyclonic meander that connects with the southward flowing circulation on the western coast and confines the inflow from the south in the meridional part of the NASM model domain. The corresponding AIM summer average (Fig. 15c) indicates that this feature is weakly occurring also in this simulation. Along the western coast, on the contrary, the two models still produce a consistent circulation pattern characterized by the WACC current that, in the NASM sim- 

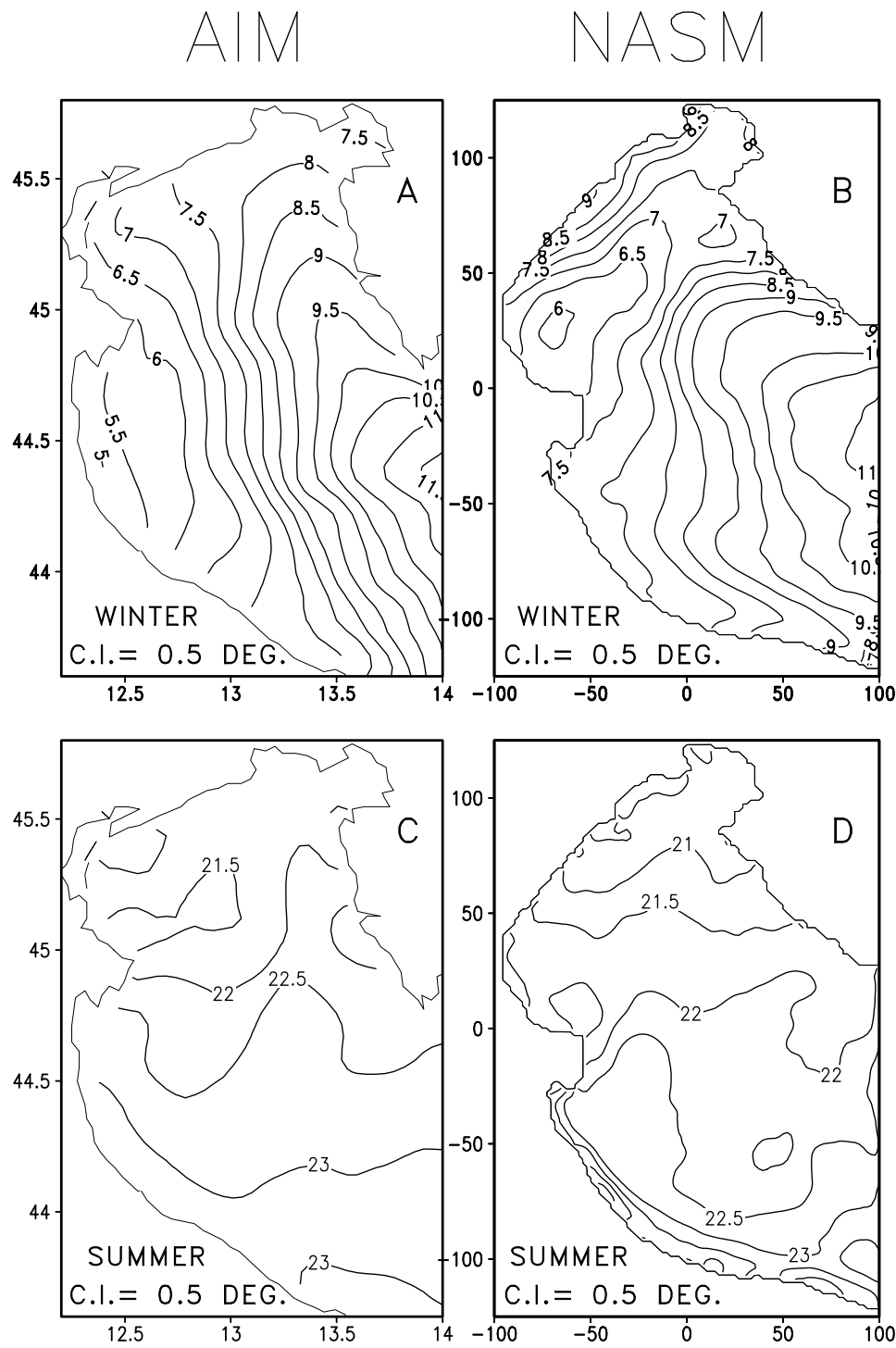

Fig. 17. Northern Adriatic Shelf Model (NASM) surface temperature distribution compared with the corresponding AIM simulation. (A): AIM winter, (B): NASM winter, (C): AIM summer, (D): NASM summer. Contour interval is $0.5^{\circ} \mathrm{C}$. Seasons definition as in Artegiani et al. (1997a). ulation, appears, also in this season, narrower than in the AIM. The occurrence of a southward current along the eastern northern Adriatic coast (named Istrian Coastal Countercurrent, ICCC) in summer has been recently described by Supic et al. (2000) by means of in situ current measurements and dynamic height computation. The circulation pattern that they describe for the summer occurrence of the ICCC resembles closely the NASM simulation results and, to a lesser extent, AIM circulation features. It has to be stressed, however, that the seasonal averages shown in Fig. 15 are smoothing out rather strongly the circulation features produced by the two models. In fact, the monthly averages of the surface circulation field relative to September (Fig. 16) show that in both AIM and NASM, the ICCC emerges as part of a completely closed anticyclonic gyre. The gyre is smaller and less spatially extended in the AIM simulation (Fig. 16a) than that in the corresponding NASM field (Fig. 16b). It might be then that NASM, with a better horizontal resolution, is produc- ing an element of the northern Adriatic summer circulation that AIM cannot capture. This is a point that obviously will deserve a close analysis in the planned future simulation experiments.

The AIM September circulation field (Fig. 16a) also accounts for the summer variability of the WACC path, a feature that does not appear clearly in Fig. 5b due to the smoothing arising from the seasonal average. It can be noted that in September the WACC partially detaches from the coast, strongly meanders and forms (in agreement with observation) southward of the Po River delta, both cyclonic and anticyclonic eddies.

The surface NASM temperature distribution (compared with AIM) is shown in Fig. 17. The NASM winter field (Fig. 17b) reproduces the cooler temperatures in the northern and western coastal regions. With respect to the AIM simulation (Fig. 17a), NASM produces a surface field characterized by slightly higher temperature with a patch of water 

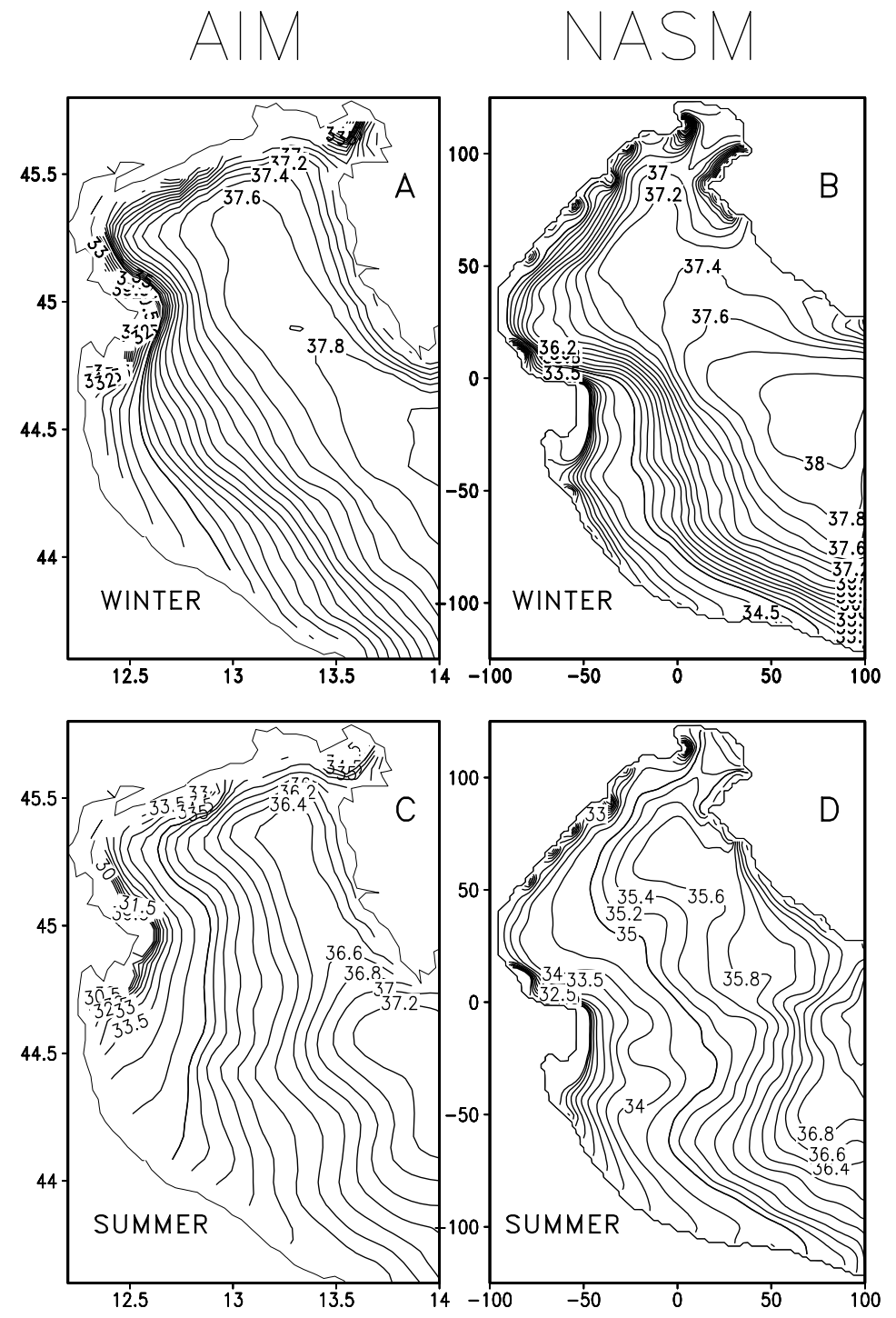

Fig. 18. Northern Adriatic Shelf Model (NASM) surface salinity distribution compared with the corresponding AIM simulation. (A): AIM winter, (B): NASM winter, (C): AIM summer, (D): NASM summer. Contour interval is $0.5 \mathrm{psu}$ for salinity values $<35.0$ psu and 0.2 psu for salinity values $>35.0$ psu. Seasons definition as in Artegiani et al. (1997a). having the minimum temperatures in good agreement with the observations of Artegiani et al. (1997b). In summer the NASM surface (Fig. 17d) temperature is again in very good agreement with the corresponding AIM field and with the climatological observations.

Comparison of the NASM and AIM salinity fields confirms the close similarities between the two models in winter (Fig. 18a and b). NASM is, however, resolving better the fresh water contribution of the rivers discharging along the northern coast, since the individual river plumes can be noted both in summer and winter. From winter to summer the generalized freshening of the basin is reproduced by NASM (Fig. 18d) in a different fashion than from AIM (Fig. 18c), both in terms salinity values (NASM surface salinities are fresher) and in terms of horizontal distribution. Part of this difference can be explained in terms of the differences in the circulation patterns described above, since the NASM occurrence of the ICCC prevents the inflow along the eastern coast of saltier water, that in AIM is advected northward. The
NASM development of the ICCC prevents this contribution and determines the lower surface salinities.

\section{Conclusions}

In this paper, we have shown the first results of a modelling effort aimed at simulating the general circulation of the whole Adriatic Sea and of the northern Adriatic basin, making use of a hierarchy (OGCM, AIM and NASM) of nested numerical models coupled through a simple one-way, offline nesting technique. The accomplishment of the numerical simulation carried out under climatological forcing allowed the evaluation of the effectiveness of the nesting technique and the understanding to which extent the system is able to reproduce the climatological characteristics of the Adriatic Sea circulation. Concerning the first point, we can conclude that the nesting of the models is working properly; the only problem (OGCM to AIM nesting during summer) might be 
due to differences in the treatment of the short-wave radiation component of the heat flux in the two models. On the contrary, the AIM to NASM nesting allowed for a "clean" downscaling of the AIM circulation features on the NASM open boundary.

The AIM simulated circulation features are consistent with the known characteristics of the Adriatic Sea circulation, with the only difference being the reduced seasonal variability of the WACC. However, the model has correctly reproduced the overall cyclonic circulation, the seasonal cycle of the scalar properties, and the dense water formation in the northern and southern Adriatic and the Otranto strait exchanges. Simulations with NASM showed, for the winter season, a strong degree of similarity with AIM. We can say that the finer NASM resolution and the effectiveness of the AIM coupling allowed for a simulation of the WACC northern Adriatic segment of superior quality with respect to AIM. This also applies to the simulation of the fresh water contribution from the Adriatic rivers. However, we have also described a strong difference between AIM and NASM in terms of surface circulation. NASM developed during summer a feature comparable with the "Istrian Coastal Countercurrent" that is only weakly appearing in the AIM simulations. The occurrence of this feature generates consistent differences between the AIM and NASM surface temperature and salinity fields. This is interpreted in terms of a better skill of NASM (due to its finer resolution) to capture features of the northern Adriatic coastal circulation.

Acknowledgements. This research has been undertaken in the framework of the EU funded Mediterranean Forecasting System Pilot Project, MFSPP (contract MAS3-CT97-0171). We thank the two reviewers for their helpful and constructive criticisms.

The Editor in Chief thanks B. Cushman-Roisin and another referee for their help in evaluating this paper.

\section{References}

Artegiani, A., Azzolini, R., and Salusti, E.: On the dense water in the Adriatic Sea, Oceanol. Acta, 12, 151-160, 1989.

Artegiani, A., Bregant, D., Paschini, E., Pinardi, N., Raicich, F., and Russo, A.: The Adriatic Sea general circulation. Part I: Air Sea interactions and water mass structure, J. Phys. Oceanogr., 27, 1492-1514, 1997a

Artegiani, A., Bregant, D., Paschini, E., Pinardi, N., Raicich, F., and Russo, A.: The Adriatic Sea general circulation. Part II: Baroclinic circulation structure., J. Phys. Oceanogr., 27, 1515-1532, 1997b.

Bignami, F., Marullo, S., Santoleri, R., and Schiano, M. E.: Longwave radiation budget in the Mediterranean Sea., J. Geophys. Res., 100, 2501-2514, 1995.

Blumberg, A. F. and Mellor, G. L.: A description of a threedimensional coastal ocean circulation model. In: Threedimensional coastal ocean models, (Ed) Heaps, N. S., AGU, 116, 1987.

Brankart, J. M. and Pinardi, N.: Abrupt cooling of the Mediterranean Levantine Intermediate Water at the beginning of the 1980's: Observational evidence and model simulation, J. Phys. Oceanogr., 31, 2307-2320, 2001.
Castellari, S., Pinardi, N., and Leaman, K.: A model study of air-sea interactions in the Mediterranean Sea, J. Mar. Sys., 18, 89-114, 1998.

Cavaleri, L., Lavagnini, A., and Martorelli, S.: The wind climatology of the Adriatic Sea deduced from coastal stations, Nuovo Cimento, 19, 37-50, 1996.

Cavaleri, L. and Bertotti, L.: In search of the correct wind and wave fields in a minor basin, Mon. Weather Rev., 125, 1964-1975, 1997.

Da Silva, A. M., Young, C. C., and Levitus, S.: Atlas of surface marine data. NOAA Atlas NESDIS, 7, pp. 78, 1995.

Demirov, E. and Pinardi, N.: Simulation of the Mediterranean Sea circulation from 1979 to 1993: Part I. The interannual variability, J. Mar. Sys., 33/34, 23-50, 2002.

Flather, R. A.: A tidal model of the northwest European continental shelf, Mém. Soc. R. Sci. Liège, 6(X), 141-164, 1976.

Franco, P.: Oceanography of the northern Adriatic Sea: II. Hydrologic features: cruises January-February and April-May 1966 , Archo. Oceanogr. Limnol., Suppl., 17, 1-97, 1972.

Franco, P. and Bregant, D.: Ingressione invernale di acque dense nord Adriatiche nella fossa di Pomo, Atti IV Congr. Assoc. Ital. Oceanogr. Limnol., 1-10, 1980.

Gacic, M., Civitarese, G., and Ursella, L.: Spatial and seasonal variability of water and biogeochemical fluxes in the Adriatic Sea. In: The Eastern Mediterranean as la laboratory basin for the assessment of contrasting ecosystems, (Eds) Malanotte-Rizzoli, P. and Eremeev, V. N., Kluwer Acad. Publ., 335-357, 1999.

Galperin, B., Kantha, L. H., Hassid, S., and Rosati, A.: A quasiequilibrium turbulent energy model for geophysical flows., J. Atmos. Sci., 45, 55-62, 1988.

Gibson, J. K., Kallberg, P. K., Uppala, S., Hernandez, A., Nomura, A., and Serrano, E.: ERA description. ECMWF Reanalysis Project Report Series, 1, pp. 72, 1997.

Hellerman, S. and Rosenstein, M.: Normal monthly wind stress over the world ocean with error estimates, J. Phys. Oceanogr., 13, 1093-1104, 1983

Jerlov, N. G.: Marine Optics, Elsevier Science, pp. 231, 1976.

Killworth, P. D.: Deep convection in the world ocean, Rev. Geophys. Space Phys., 21, 1-26, 1983.

Killworth, P. D.: Time interpolation of forcing fields in ocean models, J. Phys. Oceanogr., 26, 136-143, 1996.

Kondo, J.: Air-sea bulk transfer coefficients in diabatic conditions, Boundary Layer Meteorol., 9, 91-112, 1975.

Korres, G. and Lascaratos, A.: A one way nested eddy resolving model of the Aegean and Levantine basins: Implementation and climatological runs, Ann. Geophysicae, this issue, 2003.

Kovacevic, V., Gacic, M., and Poulain, P. M.: Eulerian current measurements in the Strait of Otranto and in the southern Adriatic, J. Mar. Sys., 20, 255-278, 1999.

Legates, D. R. and Wilmott, C. J.: Mean seasonal and spatial variability in a gauge corrected global precipitation, Int. J. Climatol., $10,121-127,1990$.

Maggiore, A., Zavatarelli, M., Angelucci, M. G., and Pinardi, N.: Surface heat and water fluxes in the Adriatic Sea: Seasonal and interannual variability, Phys. Chem. Earth, 23, 561-567, 1998.

Malanotte Rizzoli, P.: The northern Adriatic Sea as a prototype of convection and water mass formation on the continental shelf. In: Deep convection and deep water formation in the Oceans, (Eds) Chu, P. C. and Gascard, J. P., Elsevier Oceanography Series, 57, 229-239, 1991.

Manca, B. B., Kovacevic, V., Gacic, M., and Viezzoli, D.: Dense water formation in the southern Adriatic Sea and spreading into 
the Ionian Sea in the period 1997-1999, J. Mar. Sys., 33/34, 133154, 2001.

Marchesiello, P., Mc Williams, J. C., and Shchepetkin, A.: Open boundary conditions for long-term integration of regional oceanic models, Ocean Modelling, 3, 1-20, 2001.

Mellor, G. L.: An equation of state for numerical models of oceans and estuaries, J. Atmos. Oceanic Technol., 8, 609-611. 1991.

Mellor, G. L.: User's guide for a three-dimensional primitive equation, numerical ocean model, AOS Program Report, Princeton University, Princeton NJ, 34, 1998.

Mellor, G. L. and Blumberg, G.: Modeling vertical and horizontal diffusivities with a sigma coordinate system, Mon. Weather Rev., 113, 1279-1383, 1986.

Mellor, G. L. and Yamada, T.: Development of a turbulence closure submodel for geophysical fluid problems, Rev. Geophys. Space Phys., 20, 851-875, 1982.

Oberhüber, J. M.: The budgets of heat, buoyancy and turbulent kinetic energy at the surface of the global ocean. An atlas based on the COADS data set, Max Planck Inst. für Meteorologie Report, 15, pp. 20, 1988.

Oey, L. Y.: Eddy energetics in the Faroe-Shetland channel: a model resolution study, Cont. Shelf Res., 17, 1929-1944, 1998.

Oey, L. Y. and Chen, P.: A nested-grid ocean model: with application to the formation of meanders and eddies in the Norwegian Coastal Current, J. Geophys. Res., 97, 20 063-20 086, 1992.

Ovchinnikov, I. M., Zats, V. I., Krivosheya, V. G., Nemirosky, M. S. and Udodov, A. I.: Winter Convection in the Adriatic and formation of deep eastern Mediterranean waters, Ann. Geophysicae, 5B, 89-92, 1987.

Payne, R. E.: Albedo of the sea surface, J. Atmos. Sci., 29, 959970, 1972.

Pinardi, N., Allen, J. I., Demirov, E., De Mey, P., Korres, G., Lascaratos, A., Le Traon, P. Y., Maillard, C., Manzella, G., and Tziavos, C.: The Mediterranean ocean Forecasting System: First phase of implementation (1998-2001), Ann. Geophysicae, this issue, 2003.

Poulain, P. M.: Adriatic Sea surface circulation as derived from drifter data between 1990 and 1999, J. Mar. Sys., 29, 3-32, 2001.

Poulain, P. M. and Cushman-Roisin, B.: Circulation. In: Physical Oceanography of the Adriatic Sea. Past, present and future, (Eds) Cushman-Roisin, B., Gacic, M., Poulain, P. M., and Artegiani, A., Kluwer Academic Publ., 67-109, 2001.

Provini, A., Crosa, G., and Marchetti, R.: Nutrient export from the Po and Adige river basin over the last 20 years, Sci. Total Env., suppl., 291-313, 1992.

Pullen, J. D.: Modeling studies of the coastal circulation off north- ern California, Ph. D. Dissertation in Oceanography, Oregon State Univ., 145, 2000.

Pullen, J. D. and Allen, J. S.: Modeling studies of the coastal circulation off northern California: Shelf response to a major Eel river flood event, Cont. Shelf Res., 20, 2213-2238, 2000.

Pullen, J. D. and Allen, J. S.: Modeling studies of the coastal circulation off northern California: Statistics and patterns of wintertime flows, J. Geophys. Res., 106, 26 959-26 984, 2001.

Raicich, F.: Note on flow rates of the Adriatic rivers. Istituto Talassografico Sperimentale Trieste, Technical Report, RF02/94, pp. 8, 1994.

Raicich, F.: On the fresh water balance of the Adriatic Sea, J. Mar. Sys., 9, 305-319, 1996.

Reed, R. K.: An evaluation of formulas for estimating clear sky insolation over the ocean, NOAA-ERL 352-PMEL Techn. Rep., 26, pp. 25, 1975.

Reed, R. K.: On estimating insolation over the ocean, J. Phys. Oceanogr., 7, 482-485, 1977.

Reynolds, R. W. and Smith, T. M.: Improved global sea surface temperature analyses using optimum interpolation, J. Climate, 7, 929-948, 1994.

Rosati, A. and Miyakoda, K.: A general circulation model for upper ocean simulation, J. Phys. Oceanogr., 18, 1601-1626, 1988.

Sannino, G. M., Bargagli, A., and Artale, V.: Numerical Modeling of the mean exchange through the Strait of Gibraltar, J. Geophys. Res., 107(CB) Ant. No. 3094, 2002.

Smagorinsky, J.: Some historical remarks on the use of nonlinear viscosities. In: Large eddy simulations of complex engineering and geophysical flows, (Eds) Galperin, B. and Orszag, S., Cambridge Univ. Press, 1993.

Smolarkiewicz, P. K.: A fully multidimensional positive definite advection transport algorithm with small implicit diffusion, J. Comput. Phys., 54, 325-362, 1984.

Smolarkiewicz, P. K. and Clark, T. L.: The multidimensional positive definite advection transport algorithm: further development and applications, J. Comput. Phys., 67, 396-438, 1986.

Supic, N., Orlic, M., and Degobbis, D.: Istrian coastal countercurrent and its year to year variability, Est. Coast. Shelf Sci., 51, 385-397, 2000.

Vogt, J. A.: Adriatic Sea surface temperature: Satellite and drifter observations between May and October 1995. M. S. Thesis, Naval Postgraduate School Monterey, pp. 85, 2002.

Zavatarelli, M., Pinardi, N., Kourafalou, V. H., and Maggiore, A.: Diagnostic and prognostic model studies of the Adriatic Sea circulation. Seasonal variability, J. Geophys. Res., 107, Ant. No. 3004, 2002. 